SANDIA REPORT

SAND2012-1541

Unclassified Unlimited Release

Printed February 2012

Supersedes SAND2011-0973

Dated February 2011

\title{
Sandia National Laboratories, California Chemical Management Program Annual Report
} February 2012

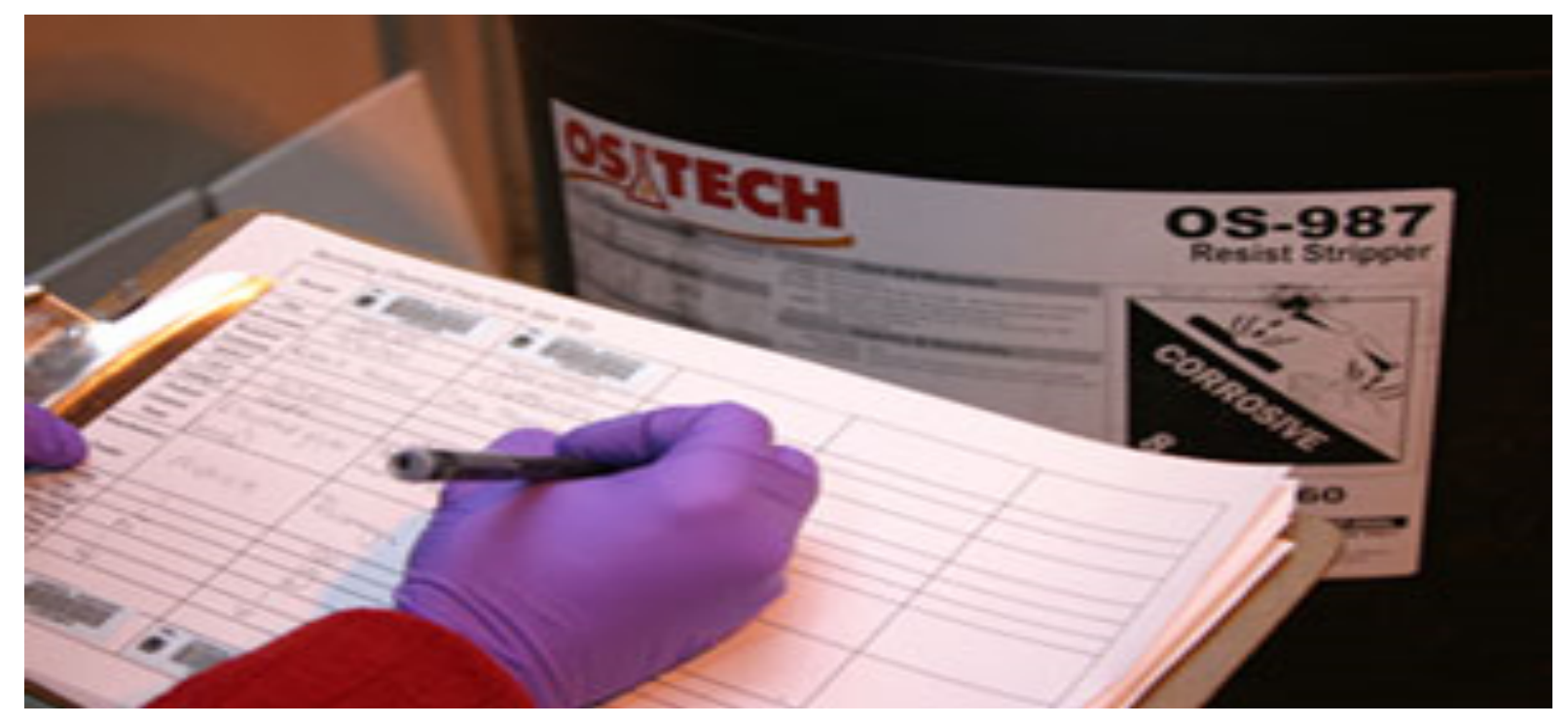

Mark E. Brynildson, SNL/CA Chemical Management Program Lead

Prepared by

Sandia National Laboratories

PO Box 969 MS 9902

Livermore, California 94551-0969

Sandia National laboratories is a multi-program laboratory managed and operated by Sandia Corporation, a wholly owned subsidiary of Lockheed Martin Corporation, for the United States Department of Energy's

National Nuclear Security Administration under contract DE-AC04-94AL85000.

Approved for public release, further dissemination unlimited

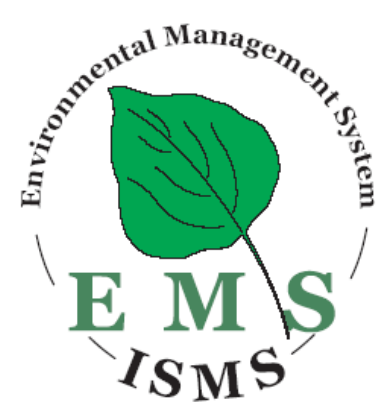

\section{Sandia National Laboratories}


Issued by Sandia National Laboratories, operated for the United States Department of Energy by Sandia Corporation.

NOTICE: This report was prepared as an account of work sponsored by an agency of the United States Government. Neither the United States Government, nor any agency thereof, nor any of their employees, nor any of their contractors, subcontractors, or their employees, make any warranty, express or implied, or assume any legal liability or responsibility for the accuracy, completeness, or usefulness of any information, apparatus, product, or process disclosed, or represent that its use would not infringe privately owned rights. Reference herein to any specific commercial product, process, or service by trade name, trademark, manufacturer, or otherwise, does not necessarily constitute or imply its endorsement, recommendation, or favoring by the United States Government, any agency thereof, or any of their contractors or subcontractors. The views and opinions expressed herein do not necessarily state or reflect those of the United States Government, any agency thereof, or any of their contractors.

Printed in the United States of America. This report has been reproduced directly from the best available copy.

Available to DOE and DOE contractors from

U.S. Department of Energy

Office of Scientific and Technical Information

P.O. Box 62

Oak Ridge, TN 37831

Telephone: (865) 576-8401

Facsimile: (865) 576-5728

E-Mail: $\quad$ reports@adonis.osti.gov

Online ordering: http://www.doe.gov/bridge

Available to the public from

U.S. Department of Commerce

National Technical Information Service

5285 Port Royal Road

Springfield, VA 22161

Telephone: (800) 553-6847

Facsimile: (703) 605-6900

E-Mail: $\quad$ orders@ntis.fedworld.gov

Online order: http://www.ntis.gov/ordering.htm
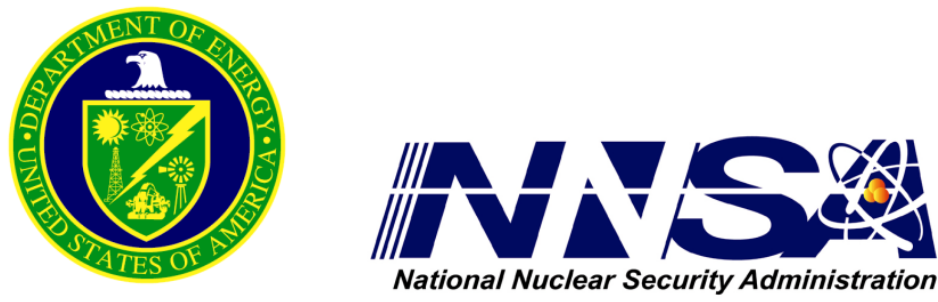
SAND2012-1541

Unclassified Unlimited Release

Printed February 2012

\title{
Sandia National Laboratories, California Chemical Management Program Annual Report February 2012
}

\author{
Mark E. Brynildson, \\ SNL/CA Chemical Management Program Lead \\ Environmental Management Department \\ Sandia National Laboratories, California
}

\begin{abstract}
The annual program report provides detailed information about all aspects of the Sandia National Laboratories, California (SNL/CA) Chemical Management Program. It functions as supporting documentation to the SNL/CA Environmental Management System Program Manual. This program annual report describes the activities undertaken during the calender past year, and activities planned in future years to implement the Chemical Management Program, one of six programs that supports environmental management at SNL/CA.
\end{abstract}




\section{Acknowledgement}

The author thanks Gary Shamber, Manager, Environmental Management Department, Susanne Ayers, Chemical Management Program Senior Technologist and the Environmental Management Department personnel for their leadership, guidance and support in the responsible stewardship of the environmental resources in our care. 
Table of Contents

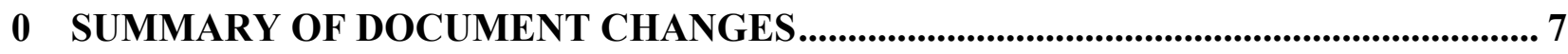

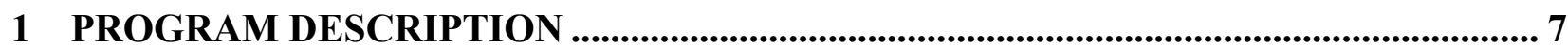

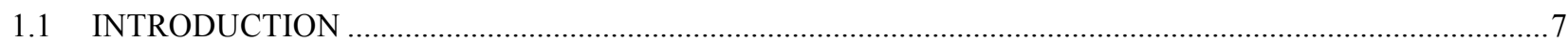

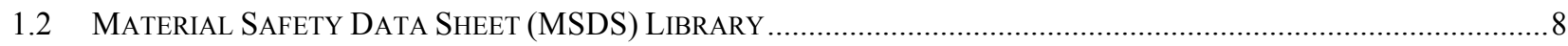

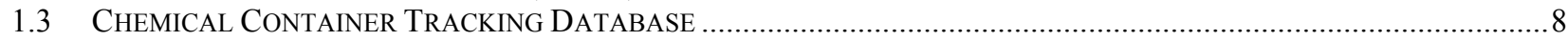

2 REGULATORY / CORPORATE DRIVERS ..................................................................9

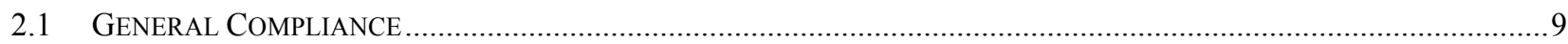

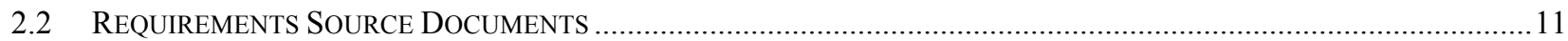

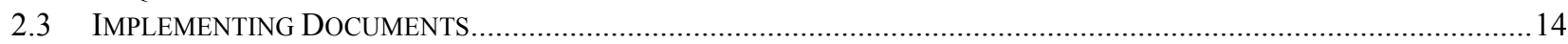

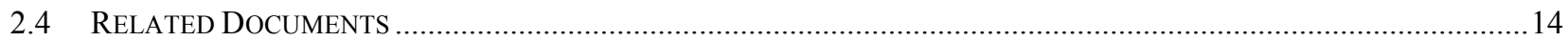

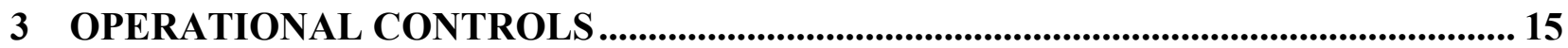

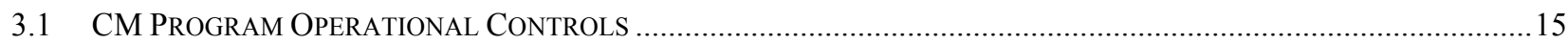

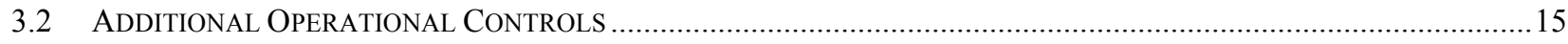

4 DOCUMENTS PRODUCED .................................................................................. 15

5 APPROVED JOB DESCRIPTIONS / CURRENT ASSIGNMENTS ............................. 16

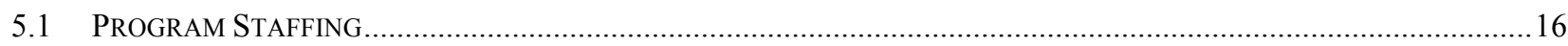

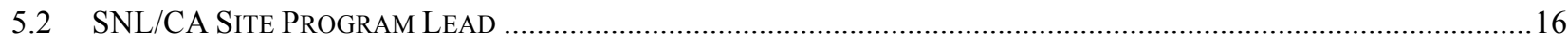

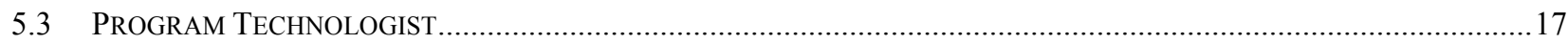

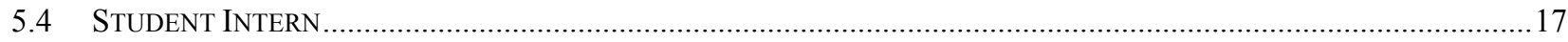

6 TRAINING AND COMPETENCY ........................................................................... 18

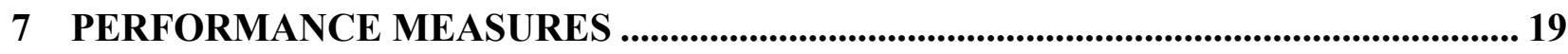

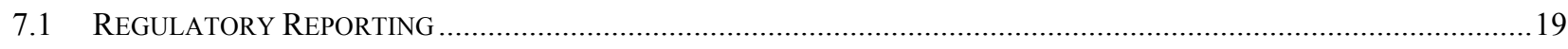

7.2 ANNUAL CHEMICAL INVENTORY RECONCILIATION “FoUND” RATE …….........................................................19

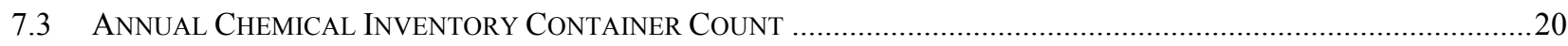

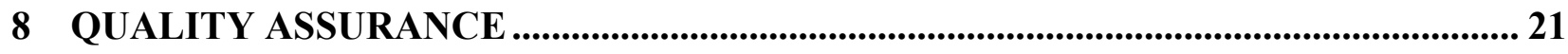

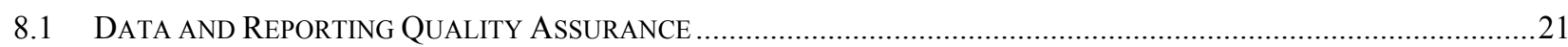

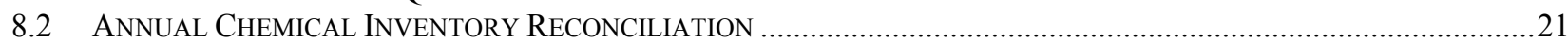

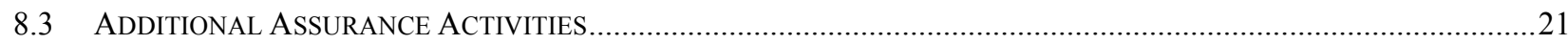

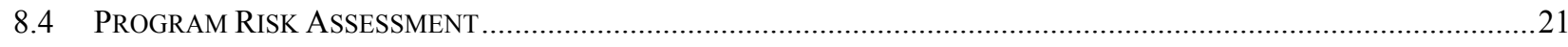

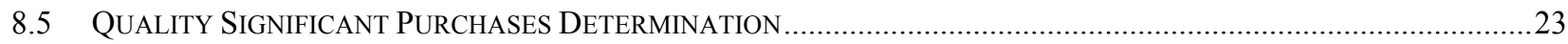

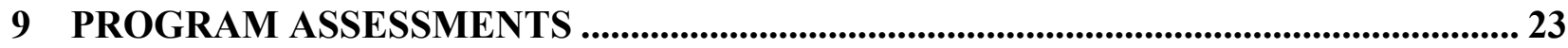

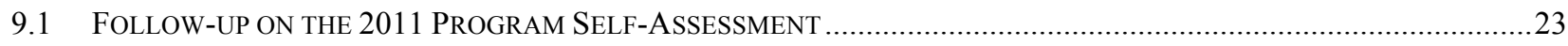

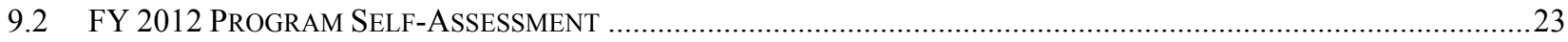

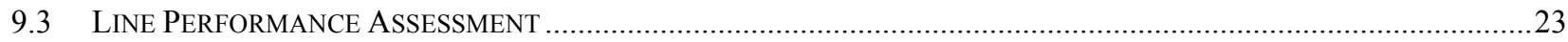

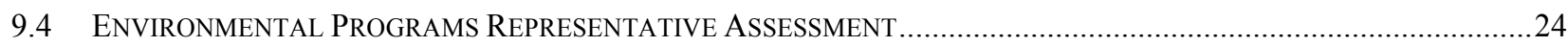

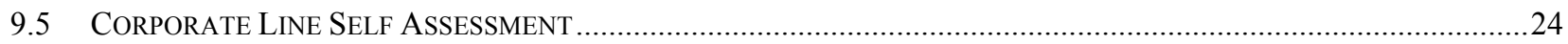

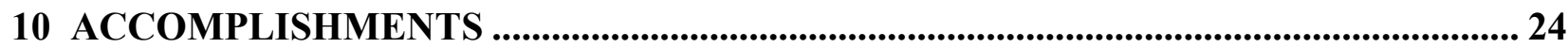

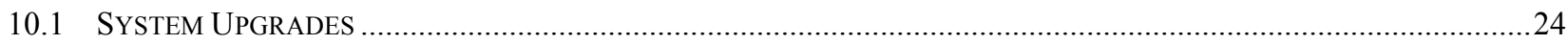

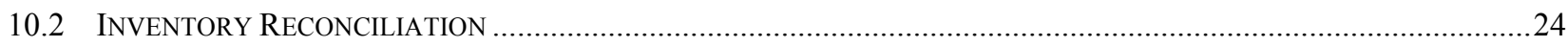

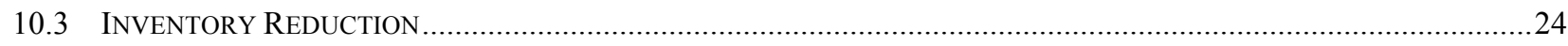

10.4 EMERGENCY MANAGEMENT - HAZARDS SURVEY …….........................................................................2

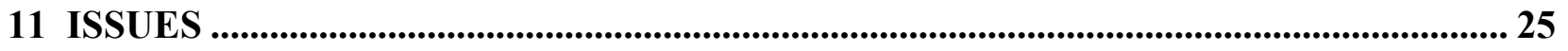




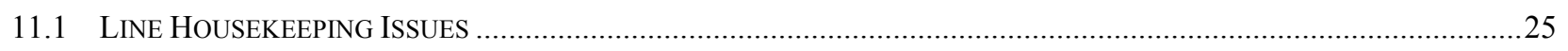

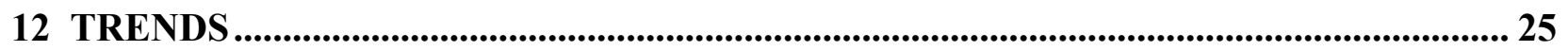

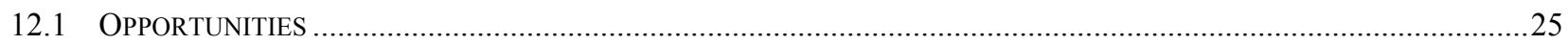

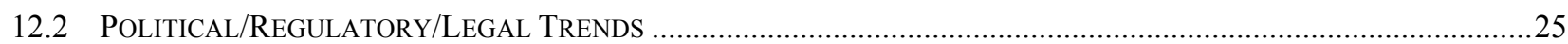

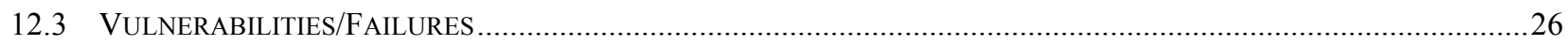

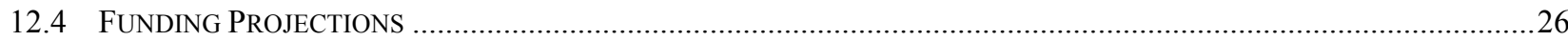

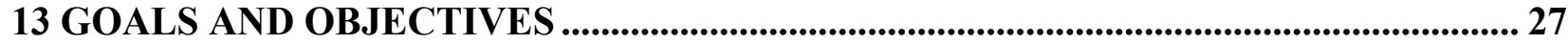

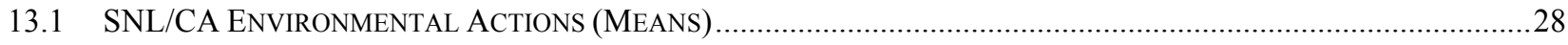

APPENDIX A. PERSONNEL ASSIGNMENTS ....................................................................... 32

APPENDIX B. CHEMICAL MANAGEMENT PROGRAM RISK ASSESSMENT ............. 33 APPENDIX C. CHEMICAL MANAGEMENT QUALITY SIGNIFICANT PURCHASES

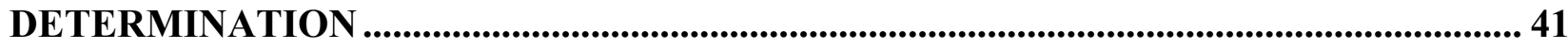

APPENDIX D. CHEMICAL MANAGEMENT PROGRAM SELF ASSESSMENT ........... 43

APPENDIX E. CHEMICAL MANAGEMENT PROGRAM SELF ASSESSMENT DOCUMENT CHECKLIST ...................................................................................................... 47

\section{Figures}

Figure 7-1. Annual Chemical Inventory Reconciliation "Found" Rate................................19

Figure 7-2. Annual Chemical Inventory Container Count.........................................................20

\section{Tables}

Table 0-1 Summary of Significant Changes to the Chemical Management Program Report7

Table 2-1 Significant Compliance Drivers for the Chemical Management Program.........10

Table 3-1 Technical Work Documents Applicable to the CM Program ...............................15

Table 4-1 CM Program Documents Produced ..........................................................................15

Table 6-1 CM Program Training Matrix ...........................................................................................18

Table 8-1 Chemical Management Program Risks 2011 ..............................................................22 


\section{Summary of Document Changes}

Significant changes made to this Chemical Management (CM) Program Report are summarized in Table 1.

Table 0-1 Summary of Significant Changes to the Chemical Management Program Report

\begin{tabular}{|lll|}
\hline Section & Page & Change \\
\hline Various & Various & Hazardous Materials Management revised to Chemical Management \\
\hline 1.1 & 7 & Updated corporate program owner \\
\hline $1.2,1.3$ & 8,9 & Updated corporate procedure link \\
\hline 12.2 & 25 & Political/Regulatory/Legal Trends updated \\
\hline 13.1 & 28 & EMS Objective \& Targets updated \\
\hline Table $3-1$ & 15 & TWD table updated \\
\hline Table $4-1$ & 15 & Document table updated \\
\hline Table $6-1$ & 18 & CMP Training Matrix updated \\
\hline Table $8-1$ & 22 & CMP Risks updated \\
\hline Appendix B & 34 & Risk Assessment Updated \\
\hline Appendix D & 44 & CMP Self Assessment Report updated \\
\hline Appendix E & 51 & CMP Assessment Document Checklist updated \\
\hline
\end{tabular}

\section{Program Description}

\subsection{INTRODUCTION}

The CM Program is one of six programs under the Environmental Management Department at Sandia National Laboratories, California (SNL/CA). The program applies to all projects and activities involving chemicals, excluding explosives and radioactive materials, at SNL/CA. The program is part of the corporate CIS Program known as the "Chemical Information System Program" at Sandia National Laboratories/New Mexico (SNL/NM) managed by the Environmental Programs Department (04143).

SNL/CA is responsible for tracking chemicals (chemical and biological materials), providing Material Safety Data Sheets (MSDS) and for regulatory compliance reporting according to a variety of chemical regulations. The principal regulations for chemical tracking are the Emergency Planning Community Right-to-Know Act (EPCRA) and the California Right-toKnow regulations. The regulations, the Hazard Communication/Lab Standard of the Occupational Safety and Health Administration (OSHA) are also key to the CM Program. The CM Program is also responsible for supporting chemical safety and information requirements for a variety of Integrated Enabling Services (IMS) programs primarily the Industrial Hygiene, Waste Management, Fire Protection, Air Quality, Emergency Management, Environmental Monitoring and Pollution Prevention programs. 
The principal program tool is the Chemical Information System (CIS). The system contains two key elements: the MSDS library and the chemical container-tracking database that is readily accessible to all Members of the Sandia Workforce.

\subsection{Material Safety Data Sheet (MSDS) Library}

The MSDS library in CIS contains over 100,000 MSDSs, which is comprised of commercial MSDS documents and data supplemented with vendor specific MSDS images and data. The MSDS library is available on Sandia's unclassified internal/external web (login required) 24 hours a day, seven days a week with new MSDSs being added as available or by request. The CIS database and ES\&H archives store MSDSs for a period of 75 years according to a DOE epidemiological record destruction moratorium requirement. Manufacturer-specific MSDSs are maintained for products if their MSDS is not available in the commercial library. Just-In-Time (JIT) vendors with contractual chemical tracking requirements are required to provide MSDSs to the CM Program. Chemical users also send MSDSs that accompany their chemical shipments to the CM Program as outlined in Corporate Policy: ESH100 Environmental Safety \& Health, ESH100.2.ENV.27 Maintain an Accurate Chemical and Biological Material Inventory. In addition, the CM Program request MSDSs from manufacturers as needed or utilize commercially available MSDS library references. MSDSs for new chemical mixtures can be authored in-house by request. The CM Program processes MSDSs according to internal program procedures.

The web link for access to the MSDS library is:

http://cis.sandia.gov

\subsection{Chemical Container Tracking Database}

The CIS database tracks individual chemical containers with the use of unique chemical inventory barcodes. There are over 30,000 barcoded containers at SNL/CA distributed site-wide managed by nearly every SNL/CA organization. Each individual chemical container, as defined by ESH100.2.ENV.27 Maintain an Accurate Chemical and Biological Material Inventory is barcoded and all relevant chemical inventory information is collected and entered in the CIS database. Information collected includes chemical or product name, vendor, storage location, quantity, chemical owner/requester information, and container storage information for regulatory reporting purposes.

This electronic inventory allows chemical users and Integrated Mission Support (IMS) professionals to assess and manage workplace hazards. CIS data is also key in completing annual federal and state regulatory reporting requirements. Easy access to this inventory facilitates quick availability searches, sharing of chemicals, source reduction, as well as minimizing chemical purchases and waste disposal expenses.

Chemical tracking in CIS is based on the premise that if the baseline inventory is known and all incoming and outgoing chemical are tracked, the inventory will be up-to-date at any given time. All SNL sites complete annual wall-to-wall chemical inventory reconciliation. The SNL/CA 2011 reconciliation "found" percent was 94\% compared to 95\% in 2010 and $95 \%$ in 2009 . 
Just-In-Time (JIT) gas products vendor, Matheson Tri-Gas, barcodes all incoming gas products and forwards the chemical inventory information to the CM Program electronically. JIT liquid and solid products vendor, Government Scientific Sources (GSS), barcodes all incoming liquid and solid products and forwards the chemical inventory information to the CM Program electronically. The CM Program and/or Line chemical users are responsible for barcoding all other incoming chemicals (non-JIT purchases). Chemical users forwards inventory information to the CM Program using the corporate Chemical Inventory Incoming Form or the "Add Chemical Inventory" on the CIS home page. Chemical users are responsible for storage location changes if a chemical is used, disposed, or transferred to a new location. See ESH100.2.ENV.27 Maintain an Accurate Chemical and Biological Material Inventory for responsibilities and procedures for chemical users. Chemical tracking requirements are part of the contract requirements in the JIT vendor contract. The CM Program processes inventory information according to internal CM procedures.

\section{Regulatory / Corporate Drivers}

Compliance drivers include laws, regulations, orders, directives and other corporate and sitespecific requirements. The drivers that are applicable to the CM Program are listed in Table 1.

\subsection{General Compliance}

The CM Program uses a variety of sources to stay current on applicable compliance drivers. The primary source used is the Sandia corporate notification service provided by the SNL/NM ES\&H Research Librarian. The Research Librarian monitors DOE requirements and federal, state, and local government publications for regulatory issues applicable to Sandia operations. These notifications are then reviewed for applicability to SNL/CA operations. The CM Program also receives additional sources of information on regulatory changes include direct communication with DOE and regulating agencies, and periodic review of agency web sites. New requirements are incorporated into program activities and communicated to the site through electronic notifications, the ES\&H Interdisciplinary Team process, self-assessments, targeted presentations and program documents.

The CM Program is audited occasionally by DOE, Sandia Corporation, and Lockheed Martin, Sandia's parent company. Under California law, SNL/CA's Certified Unified Program Agency (CUPA) regulator the Livermore-Pleasanton Fire Department is required to audit the program every three years.

The CM Program Lead communicates with DOE/NNSA/SSO (SSO) counterparts regularly to keep them informed of issues and trends of importance to the program. The CM Program at SNL/CA works closely with our SNL/NM counterparts and DOE/NNSA/SSO to resolve concerns and to develop effective approaches to program implementation. The CM Program and SSO maintain an open and cooperative relationship. 


\section{Table 2-1 Significant Compliance Drivers for the Chemical Management Program}

\begin{tabular}{|c|c|c|}
\hline Driver & Summary & Regulating Authority \\
\hline \multicolumn{3}{|l|}{$\begin{array}{l}\text { Federal Laws and } \\
\text { Regulations }^{\mathrm{a}}\end{array}$} \\
\hline $\begin{array}{l}40 \text { CFR } 300 \text { - } 372 \text { Emergency } \\
\text { Planning Community Right-to- } \\
\text { Know (EPCRA) }\end{array}$ & $\begin{array}{l}\text { The regulations provide for Emergency Planning, } \\
\text { Emergency Notification, Community Right-to-Know } \\
\text { Reporting and Toxic Chemical Release Reporting for } \\
\text { hazardous chemicals at a facility. }\end{array}$ & EPA \\
\hline $\begin{array}{l}29 \text { CFR } 1910.1200 \text { Hazard } \\
\text { Communication Standard } \\
\text { (Worker Right-to-Know Rule) }\end{array}$ & $\begin{array}{l}\text { OSHA's Hazard Communication Standard (HCS) is } \\
\text { designed to ensure that information about these hazards } \\
\text { and associated protective measures is disseminated to } \\
\text { workers and employers. }\end{array}$ & OSHA \\
\hline $\begin{array}{l}29 \text { CFR } 1910.1450 \mathrm{Lab} \\
\text { Standard }\end{array}$ & $\begin{array}{l}\text { The Standard outlines the strategy for laboratories to } \\
\text { maintain employee exposures at or below the } \\
\text { permissible exposure limits specified for the hazardous } \\
\text { chemicals in } 29 \text { CFR part } 1910 \text {, subpart } Z \text {. }\end{array}$ & OSHA \\
\hline $\begin{array}{l}40 \text { CFR } 68 \text { Risk Management } \\
\text { Plan }\end{array}$ & $\begin{array}{l}\text { Section } 112(\mathrm{r}) \text { of the Clean Air Act focuses on the } \\
\text { efforts to prevent the accidental release of chemicals } \\
\text { and limit the consequenses of such releases. }\end{array}$ & EPA \\
\hline \multicolumn{3}{|l|}{ Executive Orders (EO) } \\
\hline $\begin{array}{l}\text { Executive Order } 12856, \text { Federal } \\
\text { Compliance with Right-to- } \\
\text { Know Laws and Pollution } \\
\text { Prevention Requirements }\end{array}$ & $\begin{array}{l}\text { The order directs federal agencies and their facilities to } \\
\text { comply with the provisions of EPCRA and the } \\
\text { Pollution Prevention Act }\end{array}$ & $\begin{array}{l}\text { DOE as responsible } \\
\text { federal agency for } \\
\text { SNL facilities }\end{array}$ \\
\hline $\begin{array}{l}\text { Executive Order } 13423 \\
\text { Strengthening Federal } \\
\text { Environmental, Energy, and } \\
\text { Transportation Management }\end{array}$ & $\begin{array}{l}\text { The order directs federal agencies and their facilities to } \\
\text { a variety of things but the action directly relevant to } \\
\text { CM program is: Title } 3 \text {, Section } 2 \text {, (e) ensure that the } \\
\text { agency (i) reduces the quantiry of toxic and hazardous } \\
\text { chemicals and materials acquired, used, or disposed of } \\
\text { by the agency, (ii) increases diversion of solid waste as } \\
\text { approprite, and (iii) maintains cost-effective waste } \\
\text { prevention and recycling programs in its facilities }\end{array}$ & $\begin{array}{l}\text { DOE as responsible } \\
\text { federal agency for } \\
\text { SNL facilities }\end{array}$ \\
\hline \multicolumn{3}{|l|}{ DOE Directives } \\
\hline $\begin{array}{l}\text { Order 450.1A Environmental } \\
\text { Protection Program / } 2008\end{array}$ & $\begin{array}{l}\text { The order outlines the basic strategy for environmental } \\
\text { compliance at DOE facilities, requires DOE facilities } \\
\text { to implement an EMS that addresses protection of site } \\
\text { resources and long-term stewardship of these resources }\end{array}$ & DOE \\
\hline
\end{tabular}




\begin{tabular}{|c|c|c|}
\hline $\begin{array}{l}\text { Order } 151.1 \mathrm{C} \text {, Emergency } \\
\text { Management / } 2005\end{array}$ & $\begin{array}{l}\text { The order outlines the basic strategy and requirements } \\
\text { for the Emergency Management Program at DOE } \\
\text { facilities. Emergency Management Hazards Surveys } \\
\text { and Emergency Management Hazards Assessments } \\
\text { (EPHAs) require extensive CMP support. }\end{array}$ & DOE \\
\hline \multicolumn{3}{|l|}{$\begin{array}{l}\text { California Laws and } \\
\text { Regulations }^{\mathrm{a}}\end{array}$} \\
\hline $\begin{array}{l}\text { State of California, Chemical } \\
\text { Release Response Plans and } \\
\text { Inventory Law (AB 2185). }\end{array}$ & $\begin{array}{l}\text { California Health and Safety Code requires businesses } \\
\text { to provide information on hazardous substances }\end{array}$ & $\begin{array}{l}\text { Alameda County } \\
\text { Department of } \\
\text { Environmental Health }\end{array}$ \\
\hline
\end{tabular}

${ }^{\mathrm{a}}$ The effective date for federal and state regulations represents the most recent revision.

\subsection{Requirements Source Documents}

\section{CFR 300-372 Emergency Planning and Community Right-to-Know Act (EPCRA)}

The Emergency Planning and Community Right-to-Know Act (EPCRA), enacted on October 17, 1986, represents a significant first step toward a major federal role in areas previously regulated by state and local governments. EPCRA was enacted by Congress as a stand-alone provision, Title III, of the Superfund Amendments and Reauthorization Act of 1986 (SARA).

SARA Title III (EPCRA) was passed in response to concerns regarding the environmental and safety hazards posed by the storage and handling of toxic chemicals. These concerns were triggered by the disaster in Bhopal, India, in which more than 2,000 people suffered death or serious injury from the accidental release of methyl isocyanate. To reduce the likelihood of such a disaster in the United States, Congress imposed requirements on both states and regulated facilities. Facilities must notify the local emergency planning districts regarding materials stored at and released from sites.

EPCRA contains three subtitles. Subtitle A, Emergency Planning and Notification, establishes mechanisms to enable states and communities to prepare to respond to unplanned releases of hazardous substances.

Subtitle B, Reporting Requirements, contains three distinct reporting provisions concerning two different groups of chemical substances. The first two sets of reports require submission of inventory-related data on hazardous chemicals [i.e., those substances for which a Material Safety Data Sheet (MSDS) is mandated under the hazard communication regulations of the Occupational Safety and Health Administration]. The third reporting provision requires annual reporting to EPA and the state in which the reporting facility is located on environmental releases of listed toxic chemicals manufactured, processed, or otherwise used at the facility in excess of specified threshold quantities.

Subtitle C, General Provisions, contains a variety of provisions, including, but not limited to, civil, criminal, and administrative penalties for violations of the statute's reporting requirements; enforcement actions that can be brought by citizens, states, and emergency planning and 
response entities; and restrictions on an owner's or operator's rights to make trade secrecy claims in the reports required by EPCRA.

Appendix A of 40 CFR 355 defines extremely hazardous substances. Any DOE facility that manages any such substances in quantities exceeding the Threshold Planning Quantities noted in the appendix must comply with EPCRA.

Under 40 CFR 355, facilities must notify the emergency response commission that they are subject to these requirements. The facilities must notify the local emergency planning unit of releases exceeding a Reportable Quantity (RQ) of Extremely Hazardous Substances, as defined under Title III, and Hazardous Substances, as defined under CERCLA. In addition, the facilities must report their chemical inventories and provide MSDSs to the local emergency planning organizations as outlined in 40 CFR 370.

\section{CFR 1910.1200 Hazard Communication Standard.}

Chemicals pose a wide range of health hazards (such as irritation, sensitization, and carcinogenicity) and physical hazards (such as flammability, corrosion, and reactivity). OSHA's Hazard Communication Standard (HCS) is designed to ensure that information about these hazards and associated protective measures is disseminated to workers and employers. This is accomplished by requiring chemical manufacturers and importers to evaluate the hazards of the chemicals they produce or import, and to provide information about them through labels on shipped containers and more detailed information sheets known as MSDSs. All employers with hazardous chemicals in their workplaces must prepare and implement a written hazard communication program, and must ensure that all containers are labeled, employees are provided access to MSDSs, and an effective training program is conducted for all potentially exposed employees.

\section{CFR 1910.1450 Occupational Exposure to Hazardous Chemicals in Laboratories (Lab Standard).}

The standard entitled "Occupational Exposure to Hazardous Chemicals in Laboratories" (§ 1910.1450; the "Standard") applies to laboratories that use hazardous chemicals in accordance with the Standard's definitions for "laboratory use of hazardous chemicals" (2) and "laboratory scale." (3) The Standard requires these laboratories to maintain employee exposures at or below the permissible exposure limits specified for the hazardous chemicals in 29 CFR part 1910, subpart Z. At SNL/CA this is implemented by the Industrial Hygiene Program in the Corporate Procedure: ESH100.2.IH.4 "Evaluate and Control Chemical Hazards" that describes: Standard operating procedures for using hazardous chemicals; hazard-control techniques; equipmentreliability measures; employee information-and-training programs; conditions under which the employer must approve operations, procedures, and activities before implementation; and medical consultations and examinations. This document also designates personnel responsible for implementing the procedure, and specifies the procedures used to provide additional protection to employees exposed to particularly hazardous chemicals. 
Other information-collection requirements of the Standard include: Documenting exposuremonitoring results; notifying employees in writing of these results; presenting specified information and training to employees; establishing a medical-surveillance program for overexposed employees; providing required information to the physician; obtaining the physician's written opinion; using proper respiratory equipment; and establishing, maintaining, transferring, and disclosing exposure-monitoring and medical records. These collection-ofinformation requirements control employee overexposure to hazardous laboratory chemicals, thereby preventing serious illnesses and death among employees exposed to such chemicals.

\section{Executive Order 12856, Federal Compliance with Right-to-Know Laws and Pollution Prevention Requirements}

Executive Order 12856 published August 6, 1993, 58 FR 41981, directs federal agencies and their facilities to comply with the provisions of EPCRA. Thus, all DOE facilities, including national laboratories, research facilities, power administrations, and petroleum reserves, are potential reporters under EPCRA, if they meet any reporting thresholds.

\section{Executive Order 13423, Strengthening Federal Environmental, Energy, and Transportation Management}

FR Vol. 72, No. 17 published Friday, January 26, 2007 Title 3, Section 2, (e) ensure that the agency (i) reduces the quantity of toxic and hazardous chemicals and materials acquired, used, or disposed of by the agency, (ii) increases diversion of solid waste as appropriate, and (iii) maintains cost-effective waste prevention and recycling programs in its facilities.

\section{State of California, Chemical Release Response Plans and Inventory Law (AB 2185).}

The California legislature passed Assembly Bill 2185 in 1987, incorporating the provisions of SARA Title III into a state program. The legislature delegated implementation of emergency planning and community-right-to-know programs to the state Office of Emergency Services (OES). OES has in turn authorized local government agencies to implement the program. The Alameda County Department of Environmental Health is responsible for AB 2185 oversight at Sandia/CA.

AB 2185 has been codified in state law as Chapter 6.95 of the California Health and Safety Code. The chapter requires that Sandia/CA complete an annual inventory or "Business Plan" listing specified Chemical.

What Chemicals Need to Be Listed On The Inventory? Section 25501.1 of the California Health and Safety Code requires businesses to provide information on all hazardous substances on the federal Environmental Protection Agency (EPA) list at Title 49, Parts 172 and 173 of the Code of Federal Regulations. This list essentially duplicates the class of materials for which a MSDS must be produced. Thus, any chemical for which an MSDS had been produced is considered reportable under Chapter 6.95. Additionally, state law requires that businesses list materials classified as hazardous wastes on the annual inventory. 


\subsection{Implementing Documents}

Corporate Policy: ESH100 Environmental Safety \& Health, ESH100.2.ENV.27 Maintain an Accurate Chemical and Biological Material Inventory.

\subsection{Related Documents}

SNL, Chemical Safety Vulnerability Review Management Response Plan, May 27, 1994.

ESH100.2.IH.4 Evaluate and Control Chemical Hazards

ESH100.2.IH.25 Control Chemical Hazards at SNL/CA.

DOE-HDBK-1139/1-2006 September 2006 Chemical Management Volume 1 of 3

DOE-HDBK-1139/2-2006 August 2006 Chemical Management Volume 2 of 3

DOE-HDBK-1139/3-2008 July 2008 Chemical Management Volume 3 of 3 


\section{Operational Controls}

\subsection{Program Operational Controls}

The CM program uses technical work documents, administrative and engineered controls, and specialized equipment as operational controls. Table 2. lists the technical work documents applicable to the program. They include the corporate ES\&H Corporate Procedures and a Primary Hazards Screening (PHS) document.

The Summer Reconciliation is another operational control implemented to improve the quality of the inventory data and capture information about Chemical not encountered in the primary receiving process. Additional information on the reconciliation is found in Section 7.2

\subsection{Additional Operational Controls}

Additional controls are a corporate Just-in-Time purchasing contract with Matheson Tri-Gas for gas products and a Just-in-Time contract for non-gas products with Government Scientific Sources (GSS). In 2010, the SNL/CA contract with GSS was superseded by a corporate Just-inTime contract with GSS on July 1, 2010. Implementation of the new contract at SNL/CA was completed in 2011.

Table 3-1 Technical Work Documents Applicable to the CM Program

\begin{tabular}{|l|l|}
\hline Title & Current Version \\
\hline $\begin{array}{l}\text { ESH100.2.ENV.27 Maintain an Accurate Chemical and Biological } \\
\text { Material Inventory. }\end{array}$ & $12 / 07 / 2011$ \\
\hline PHS SNL0A00433 Chemical Management Program at SNL/CA & $09 / 12 / 2011$ \\
\hline AP800003 CIS/CMP Inventory Procedures at SNL/CA & $10 / 20 / 2011$ \\
\hline
\end{tabular}

\section{Documents Produced}

Table 4-1 CM Program Documents Produced

\begin{tabular}{|c|c|c|c|c|}
\hline Document & Due Date & $\begin{array}{l}\text { Frequency of } \\
\text { Submittal }\end{array}$ & Distribution & Purpose \\
\hline $\begin{array}{l}\text { California Hazardous } \\
\text { Materials Business Plan } \\
\text { /EPCRA 302, } 311 \text { and } 312 \\
\text { Reporting }\end{array}$ & March 1 & Annual & $\begin{array}{l}\text { Livermore-Pleasanton } \\
\text { Fire CUPA and Alameda } \\
\text { County Fire Dept. at } \\
\text { LLNL via the California } \\
\text { Environmental reporting } \\
\text { System (CERS) and } \\
\text { DOE/SSO }\end{array}$ & $\begin{array}{l}\text { Regulatory } \\
\text { requirement }\end{array}$ \\
\hline $\begin{array}{l}\text { EPCRA } 313 \text { Toxic } \\
\text { Release Inventory (TRI) } \\
\text { Form R }\end{array}$ & July 1 & Annual & $\begin{array}{l}\text { DOE/NNSA/SSO and } \\
\text { EPA }\end{array}$ & $\begin{array}{l}\text { Regulatory } \\
\text { requirement }\end{array}$ \\
\hline
\end{tabular}




\begin{tabular}{|l|l|l|l|l|}
\hline $\begin{array}{l}\text { Chemicals New To Room } \\
\text { Report }\end{array}$ & NA & Monthly & IH/Medical/CMP & $\begin{array}{l}\text { IMS/Line } \\
\text { Operations }\end{array}$ \\
\hline $\begin{array}{l}\text { Chemicals >=55 Gallons } \\
\text { Per Storage Room Report }\end{array}$ & NA & Quarterly & CMP & IMS Operations \\
\hline Toxic Gas Report & NA & Quarterly & CMP & IMS Operations \\
\hline Cyanide Report & NA & Quarterly & IH/Medical/CMP & IMS Operations \\
\hline Expiration Date Report & NA & Quarterly & CMP & IMS Operations \\
\hline $\begin{array}{l}\text { EOC Emergency Response } \\
\text { Report }\end{array}$ & NA & Monthly & $\begin{array}{l}\text { Emergency } \\
\text { Management/CMP }\end{array}$ & IMS Operations \\
\hline $\begin{array}{l}\text { SNL/CA Air Quality } \\
\text { Chemical Received Report }\end{array}$ & NA & Monthly & Air Quality/CMP & IMS Operations \\
\hline $\begin{array}{l}\text { SNL/CA Bay Area Toxic } \\
\text { Air Chemical Received } \\
\text { Report }\end{array}$ & & & & \\
\hline $\begin{array}{l}\text { SNL/CA Deuterium } \\
\text { Inventory Report }\end{array}$ & NA & Monthly & Air Quality/CMP & IMS Operations \\
\hline $\begin{array}{l}\text { SNL/CA Deuterium } \\
\text { RECEIVED Report }\end{array}$ & NA & Monthly & ANM Management/ & CMP \\
\hline $\begin{array}{l}\text { SNL/CA Maintenance } \\
\text { Adhesives Disposal Report }\end{array}$ & NA & Monthly & ANM Management/ & AMP Operations \\
\hline SNL/CA Peroxide Report & NA & Monthly & CMP & IMS Operations \\
\hline $\begin{array}{l}\text { SNL/CA Solvent Disposal } \\
\text { Report }\end{array}$ & NA & Monthly & Air Quality/CMP & IMS Operations \\
\hline $\begin{array}{l}\text { SNL/CA Weekly Disposal } \\
\text { Report }\end{array}$ & NA & Weekly & CMP & IMS Operations \\
\hline $\begin{array}{l}\text { SNL/CA Weekly Purchase } \\
\text { Report }\end{array}$ & NA & Weekly & IH/Security/CMP & IMS Operations \\
\hline
\end{tabular}

\section{Approved Job Descriptions / Current Assignments}

\subsection{Program Staffing}

The SNL/CA CM Program personnel consists of the part-time SNL/CA Site Program Lead, a full-time CM Technologist and one Summer Student Interns. A description and associated responsibilities for each position are described below. Current personnel assignments to these positions are found in Appendix A.

\subsection{SNL/CA Site Program Lead}

The SNL/CA CM Site Program Lead is responsible for managing and overseeing operations, administering permits, reporting requirements and developing special program activities as needed. The program lead also directs the activities of the CM Technologist who in turn directs the activities of the Student Interns in the program. Primary duties include interpretation of 
technical/scientific requirements in federal and state laws, regulations, and orders as they apply to chemical management practices; advises management, makes recommendations. Guides the development of chemical management tools and procedures to ensure that these practices are in compliance with the appropriate statutes and regulations, and that regulatory reporting requirements are met. The Program Lead also supports other IMS programs on chemical management related activities. In support of these primary duties, the Program Lead sees that Line organizations have knowledge and the tools to effectively manage their chemicals. Additional activities include general chemical consulation for ES\&H programs and the IMS Interdiscplinary Team (IDT). The Program Lead also supports the Emergency Mangement (EM) Hazards Screening/Hazards Assessment Team and serves as the "Chemical Hazards SME" for the EM Program.

\subsection{Program Technologist}

The CM program efficiently collects and manages chemical information for the Line, regulators, DOE, and ES\&H customers. This technologist provides assistance to customers, prepares regulatory compliance reports, performs data, Line and Program quality assurance and manages the Material Safety Data Sheets (MSDS). The CM Technologist also serves as the lead in the annual chemical reconciliation, supervises student interns, and manages day-to-day operations for the CM Program. An additional duty includes serving as a back-up Hazardous Waste Technologist in the Waste Management Program.

\subsection{Student Intern}

The Student Intern position has three main components: chemical inventory reconciliation and data collection and data entry. Student Interns work under the direct supervision of the CM Technologist during lab and other fieldwork. During reconciliation they visit every chemical storage location and scan the barcodes on the chemical containers, add barcodes and collect all relevant chemical data. The computer data entry portion involves entering data collected from the field and entered into the CIS. An additional component of the position entails answering calls from customers, entering information from MSDSs, locating MSDSs, and analyzing and manipulating data. Student Interns must have a positive attitude and good oral and written communication skills. Prior experience in other service organizations is desired but not required. Interns must have experience working in a chemical laboratory environment and must be an independent and self-motivated worker. Additional required skills include general computer experience and high school chemistry coursework. Must have a GPA greater than 3.2. 


\section{Training and Competency}

Table 6-1 CM Program Training Matrix

\begin{tabular}{|c|c|c|c|c|}
\hline Training Requirement & Training Method & 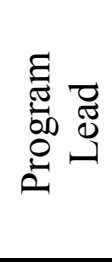 & 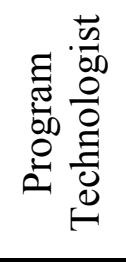 & 䓠 \\
\hline $\begin{array}{l}\text { Advanced degree in chemistry or related } \\
\text { physical/biological science }\end{array}$ & Graduate degree & $\mathrm{O}$ & $\mathrm{N}$ & $\mathrm{N}$ \\
\hline $\begin{array}{l}\text { Bachelor's degree in chemistry or related } \\
\text { physical/biological science }\end{array}$ & $\begin{array}{c}\text { Bachelor's } \\
\text { degree }\end{array}$ & $\mathrm{R}$ & $\mathrm{O}$ & $\mathrm{N}$ \\
\hline $\begin{array}{l}\text { Associates of Arts/Science degree in chemistry or } \\
\text { related physical/biological science or higher }\end{array}$ & AA/AS degree & $\mathrm{O}$ & $\mathrm{R}$ & $\mathrm{N}$ \\
\hline Certified Hazardous Materials Manager & CHMM program & $\mathrm{O}$ & $\mathrm{O}$ & $\mathrm{N}$ \\
\hline 40-hr HAZWOPPER certified & $\begin{array}{c}\text { Off-site } \\
\text { classroom }\end{array}$ & $\mathrm{R}$ & $\mathrm{R}$ & $\mathrm{N}$ \\
\hline FRP106 Fire Extinguisher Training Hands-on & SNL classroom & $\mathrm{R}$ & $\mathrm{R}$ & $\mathrm{N}$ \\
\hline $\begin{array}{l}\text { MED104CA Adult CPR and Automated External } \\
\text { Defibrillator for Non-Medical Personnel }\end{array}$ & SNL classroom & $\mathrm{R}$ & $\mathrm{R}$ & $\mathrm{N}$ \\
\hline $\begin{array}{l}\text { MED113 Blood Borne Pathogens Training for } \\
\text { Non-Medical Personnel }\end{array}$ & $\begin{array}{l}\text { SNL classroom } \\
\text { or on-line }\end{array}$ & $\mathrm{R}$ & $\mathrm{R}$ & $\mathrm{N}$ \\
\hline ESH100 ES\&H Awareness & $\begin{array}{l}\text { SNL classroom } \\
\text { or on-line }\end{array}$ & $\mathrm{R}$ & $\mathrm{R}$ & $\mathrm{R}$ \\
\hline CHM100 Chemical Safety Training & $\begin{array}{l}\text { SNL classroom } \\
\text { or on-line }\end{array}$ & $\mathrm{R}$ & $\mathrm{R}$ & $\mathrm{R}$ \\
\hline CHM103 Site Specific Chemical Safety Training & $\begin{array}{l}\text { SNL classroom } \\
\text { or on-line }\end{array}$ & $\mathrm{R}$ & $\mathrm{R}$ & $\mathrm{R}$ \\
\hline $\begin{array}{l}\text { RAD102 General Employee Radiological Training } \\
\text { or RAD230 Radiological Worker Training }\end{array}$ & $\begin{array}{l}\text { SNL classroom } \\
\text { or on-line }\end{array}$ & $\mathrm{R}$ & $\mathrm{R}$ & $\mathrm{R}$ \\
\hline ENV190 Oil Spill Plan Awareness & SNL on-line & $\mathrm{R}$ & $\mathrm{R}$ & $\mathrm{N}$ \\
\hline $\begin{array}{l}\text { ENV191 Annual Site Specific Discharge } \\
\text { Prevention Briefing }\end{array}$ & SNL classroom & $\mathrm{R}$ & $\mathrm{R}$ & $\mathrm{N}$ \\
\hline
\end{tabular}

$\mathrm{R}=$ required, $\mathrm{O}=$ Optional, $\mathrm{N}=$ Not Required 


\section{Performance Measures}

\subsection{Regulatory Reporting}

Regulatory reporting will be completed as prescribed in Table 4-1 CM Program Documents Produced.

\subsection{Annual Chemical Inventory Reconciliation “Found” rate}

The annual chemical inventory reconciliation "found" rate performance target is greater than or equal to $90 \%$. In 2011, the CM Program was just under the highest reconciliation "found rate" at $94 \%$. This exceeds the corporate performance target (90\%). The drop off from $95 \%$ is minor but it is likely related to the purposeful transfer of select inventorying activities to the Line organizations. Figure 7-1. illustrates the "found" rate performance over the last decade and shows steady progress toward a rate consistently in the low $90 \%$ range. Although improvement is desired, additional resources are needed (or redirecting existing resources) to increase Line education, increase data surveillance and improve site business processes to achieve improved results.

$\triangle$

\section{SNL/CA Site CIS Data Reconciliation}

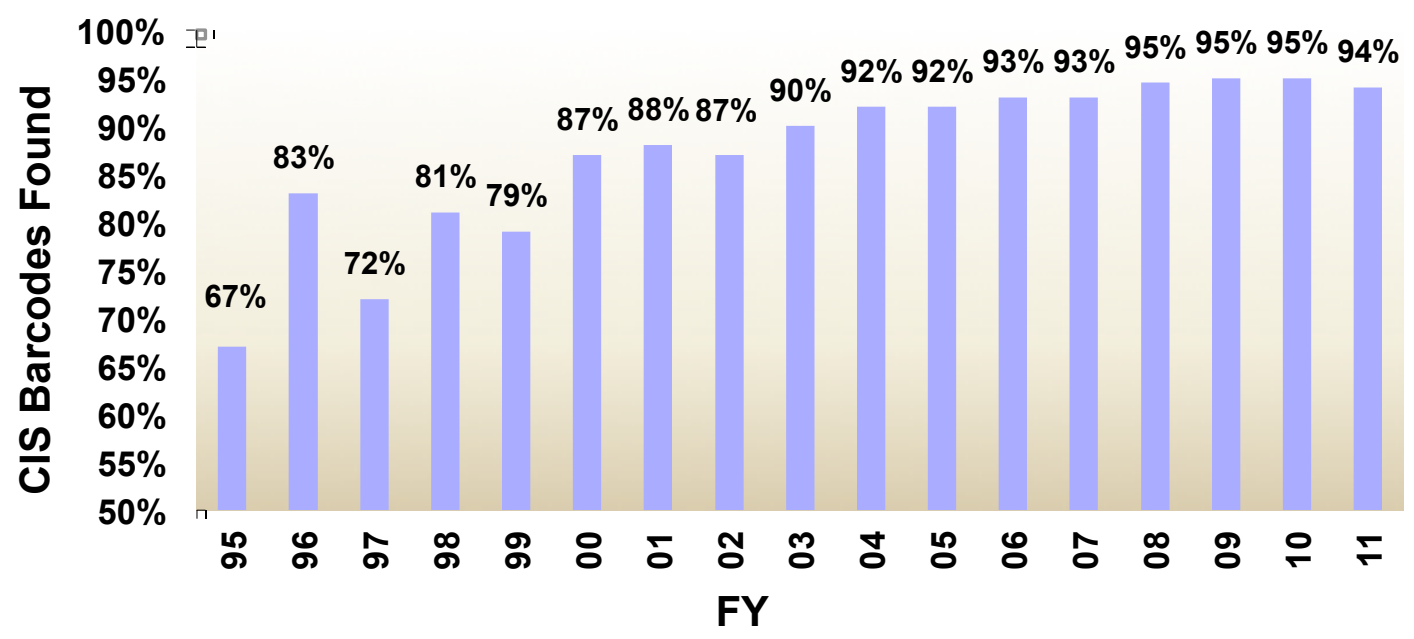

Figure 7-1. Annual Chemical Inventory Reconciliation "Found" Rate. 


\subsection{Annual Chemical Inventory Container Count}

Figure 7-2. illustrates the total site chemical container count and the site container count of NFPA Health $3 \& 4$ rated materials. The general trend observed from the first site inventory in 1994 until 2002 was the increasing of the total container count. Some of the increase was due to the improvement of the inventory process to account for more containers but the majority of the increase was likely due to the implementation of the Waste Management chargeback. The chargeback process requires waste generators to directly pay a portion or all of the cost of disposal in an effort to encourage waste minimization. The chargeback likely resulted in excessive inventories as generators avoided disposal costs and waste generation by keeping unnecessary materials in inventory. Thus, the chargeback works as a disincentive to reduce chemical inventory, essentially deferring waste disposal and requiring periodic campaigns to "right size" the chemical inventory.

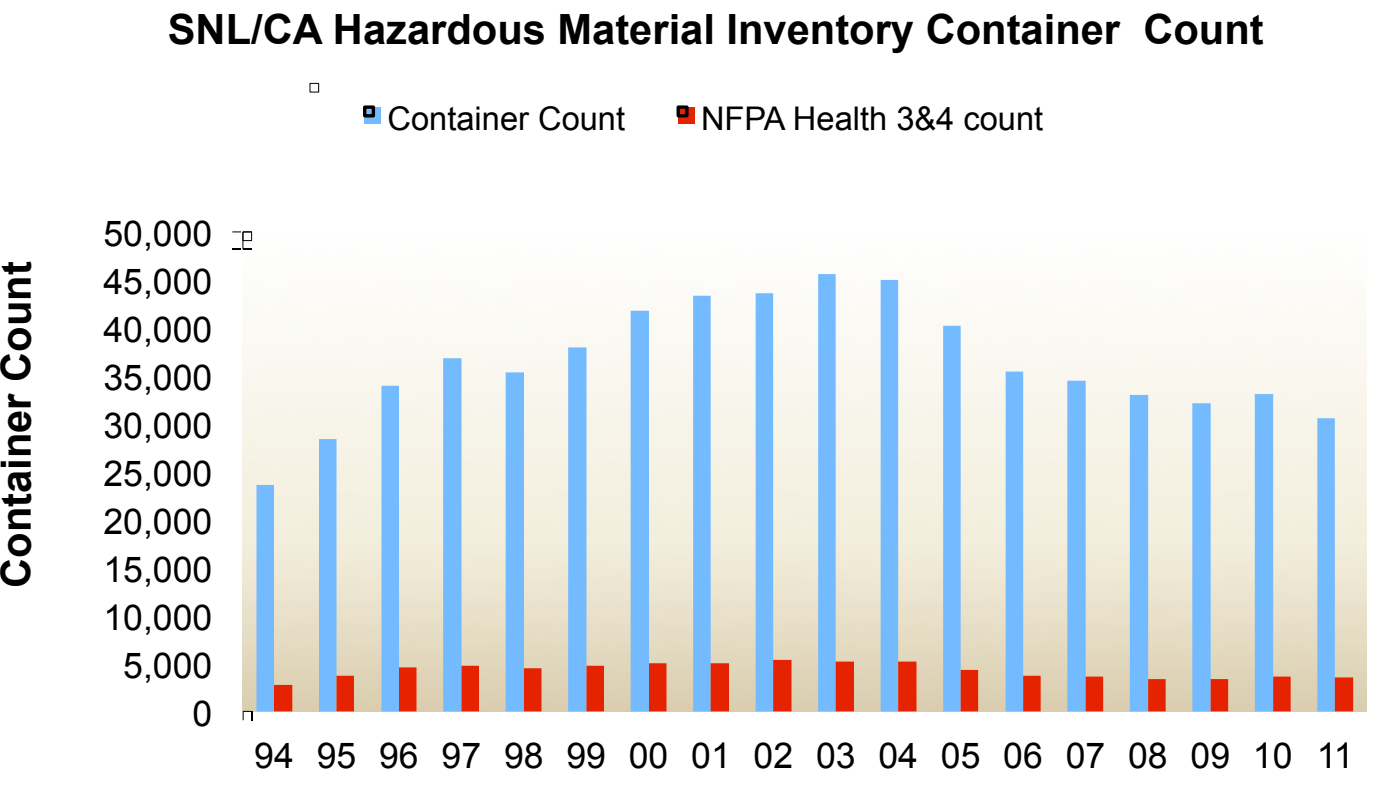

Fiscal Year

Figure 7-2. Annual Chemical Inventory Container Count 


\section{Quality Assurance}

\subsection{Data and Reporting Quality Assurance}

The CM Program applies the following program-specific elements to assure quality is maintained in data collection, analyses, and reporting.

- Online and hardcopy validation tools, screens and forms ensure that a standard process is followed for collection and management of inventory data.

- All data input is reviewed for accuracy after the input is complete.

- All regulatory lists are periodically reviewed and updated.

- Internal reports and documents are subjected to internal review and technical editing before finalizing.

- $\quad \mathrm{DOE} / \mathrm{SSO}$, applicable SNL/CA staff and technical editor's review published reports before finalizing.

\subsection{Annual Chemical Inventory Reconciliation}

Summer reconciliation is a quality assurance process where a team of Student Interns is led by the CM technologist.

- The reconciliation uses portable barcode readers to find all barcoded containers on-site.

- Reconciliation results are e-mailed to the location owners for verification.

- Location ownership is verified with the annual reconciliation.

\subsection{Additional Assurance Activities}

- Requested ad hoc reconciliations/transfers of chemical inventory are performed to assure data quality.

- Ad Hoc e-mail notification is provided to inform the resigning, retiring, or terminated employee's manager that that person was or has been responsible for specific locations and/or chemicals. This ensures that the ownership of inventory is up-to-date.

\subsection{Program Risk Assessment}

In January 2012, the CM Program updated a risk assessment (Appendix B) as part of the decision making process to determine the appropriate level of formality required for Program activities and identified seven potential risks related to program activities. Table 6 lists each risk and the calculated risk category. The overall risk for CM Program issues were determined to be medium. Measures taken by the CM Program to mitigate this risk are 1) routine CM personnel training, 2) maintaining operational controls, 3) improve processes and systems (CIS) and 4) Line training. 
Table 8-1 Chemical Management Program Risks 2011

\begin{tabular}{|c|l|l|}
\hline Risk \# & Risk & $\begin{array}{l}\text { Overall Risk } \\
\text { Category }\end{array}$ \\
\hline 1 & Chemical not being tracked in CIS & low \\
\hline 2 & Aging chemicals or containers & medium \\
\hline 3 & Chemical misidentified in CIS & low \\
\hline 4 & Storage incompatibility & medium \\
\hline 5 & Excess inventory & medium \\
\hline 6 & Site-wide Earthquake Induced Spill or Accident & low \\
\hline 7 & Reduction of program funding by 10\% & high \\
\hline 8 & Regulatory Noncompliance & low \\
\hline
\end{tabular}

For the low risk category for Risk 1, the chemicals not being tracked are usually the result of local procurement and site personnel not obtaining a barcode for the container. The risk is minimized by the summer inventory reconciliation, additional Line training of their barcoding responsibilities and tighter procurement controls restricting local purchasing.

In response to the medium risk category for Risk 2, the risk is minimized by the inventory reduction campaigns and targeted chemical safety surveillance of the peroxidizable/autopolymerizable materials.

For the low risk category for Risk 3, updating incorrect data as it is observed minimizes the risk.

For the medium risk category for Risk 4, correcting problems observed during a variety of Line assessment processes minimizes the risk.

For the medium risk category for Risk 5, the risk mitigation is addressed by an explicit annual EMS goal.

For the low risk category for Risk 6, the risk is minimized by correcting problems observed during a variety of Line assessment processes and through inventory reduction.

For the high risk category for Risk 7, the risk is minimized by a review of program activities that could be streamlined. A 10\% reduction in program funding would result in decreased staffing, training, and purchases. Only those program activities that are required by regulation, Sandia policy, technical work documents, or DOE/NNSA would be conducted. Discretionary training and travel for program staff would be eliminated. Purchases for replacement equipment and equipment repair would be reduced. A reduction in Line training and support would occur.

For the low risk category for Risk 8, the Fire Protection Program was identified during the Fall 2008 Alameda County Department of Environmental Health (SNL/CA CUPA) Assessment to be under managing chemical according to the California Fire Code (CFC). A similar situation exists with the International Fire Code (IFC) that is regulated by DOE. This situation has been improved by report modifications in CIS. Full CFC compliance, however, is difficult without 
comprehensive hazard categorization data that is not available for all the chemical on site. This identified risk is dependent on the extent the CUPA chooses to regulate the CFC at SNL/CA. All California facilities struggle with these regulations and full compliance

\subsection{Quality Significant Purchases Determination}

A Quality Significant Purchases Determination, Appendix C, has been completed in accordance with the Environmental Management Quality Assurance Program Plan. The CM Program does not have any quality significant items.

\section{Program Assessments}

\subsection{Follow-up on the 2011 Program Self-Assessment}

The 2011 Program Self Assessment identified issues with Line under-compliance with requirements and CM Program documents out-of-date. The FY2011 Program Self Assessment showed considerable improvement in up-to-date documentation. Line under-compliance in the CM program area has improved as well confirmed by the little mention of CM problems in EP Rep. Assessments and site Management Self Assessments.

\subsection{FY 2012 Program Self-Assessment}

The FY 2011 CM program self-assessment was completed in January 2012. The program selfassessment is included in Appendix D. The chemical and biomaterial procurement and the delivery of these products is a concern that was focused on the FY 2012 Program SelfAssessment. During this assessment, a review of the chemical receiving SNL/CA joint operations with LLNL and supply chain process was completed. With the initial consolidation of joint operations, problems rose in the chemical receiving operations. Since then CIS/CMP and Logistics have worked jointly to resolve these issues and come up with alternative solutions. However, one remaining issue lies with the separation of logistics and chemical receiving operations that has lead to a breakdown in communication between the two groups. Once the new corporate JIT contract is fully implemented at SNL/CA, we hope that it will improve the chemical receiving process and resolve any remaining issues.

Improvements to these processes are expected in FY2012 led by Susie Ayers.

\subsection{Line Performance Assessment}

The FY2012 Program Self Assessment did not focus on the Line but included information about procurement and logistics experienced by the Line user. This information is found in section 9.2 FY 2012 Program Self-Assessment and in Appendix D. 


\subsection{Environmental Programs Representative Assessment}

The year-round Environmental Programs Representative (EP Rep.) assessment led by the Division 8000 EP Rep. at Sandia/CA, Deanna Dicker, reports issues to the Chemical Management Program Lead. If necessary, Line Self-Assessment findings are issues. See section 9.5 for the findings CM program findings issued since they are not reported separately.

\subsection{Corporate Line Self Assessment}

The year-round corporate Line self assessment team led by the 8000 Environmental Programs Representative at Sandia/CA issued Actions to the Center 8200 personnel related to the CM program. Most were related to missing barcodes on chemical containers, old/excess chemicals and expired chemicals. These issues were all resolved by barcoding the containers. The old/excess and expired chemicals will be address in the chemical inventory reduction activities of Center 8200 in FY12. Missing barcodes are typically the result of items purchased and brought on-site by the Line and the owner fails to notify the CMP that the item needs barcoding.

\section{Accomplishments}

\subsection{System Upgrades}

The CM Program continues to actively update or enhance the CIS as needed. Minor upgrades were acomplished in several software releases during 2011. However, no major upgrade to CIS was released this year.

\subsection{Inventory Reconciliation}

The CM Program performs an annual chemical inventory reconciliation during the Summer months. In 2011, the CM program team was close to the highest "found rate" with a 94\% rate. This exceeds the corporate performance target (90\%). Chemical inventory process improvements, part of other goals, should result in a gradual improvement in the "found rate". Therefore, no specific tasks are proposed to increase the "found rate" and the performance target $(90 \%)$ remained the same in 2011.

\subsection{Inventory Reduction}

In FY2011, a new approach to inventory management was approved and implemented. On 4/5/2011, SSHEAC approved new SNL/CA site FY12 Environmental Management System (EMS) targets designed to reduce the site inventory of old and expired chemicals. "Expired Chemicals" will be expected to be eliminated entirely. Chemicals between 10-15 years old will be reduced to no greater than $15 \%$ of the chemical inventory and chemicals older than 15 years no greater than $10 \%$ of the chemical inventory. Centers will be required to report their status annually to SSHEAC on their Center Annual Report. Significant progress has been made but more reduction needs to be accomplished to meet the site targets. 


\subsection{Emergency Management - Hazards Survey}

A Hazards Survey compliant with DOE O 151.1C was completed by the SNL/NM Emergency Management Program. This effort was supported by the CM Program through document and data reviews. In 2011, the CM program also continued to support the Emergency Management Program by staffing the Chemical Hazards SME and the ES\&H Field team activities.

\section{Issues}

\subsection{Line Housekeeping Issues}

The most significant program issue continues to fall in the general category of Line chemical storage housekeeping. General housekeeping issues continue to be the focus in the DOE initiative started several years ago on Unneeded Materials and Chemicals. At SNL/CA, some Line chemical storage locations are kept in good condition. However, some are neglected and overstocked with unneeded and often unusable materials. Some of the neglected locations also include hazards such as Black Widow spiders, rodent feces and excess equipment that add significant personnel safety issues and operational inefficiencies.

\section{Trends}

\subsection{Opportunities}

The CM Program's greatest advancement opportunity came from the implementation of the modernized CIS software. In 12/2004 the team introduced a robust set of tools in the new CIS software that allow for much greater effectiveness in the management of the chemical inventory. These tools also provide an unprecedented opportunity to gather information about the inventory. This information can be used principally by the ES\&H Subject Matter Experts (SMEs) to manage their programs more effectively. One example of this is the Emergency Planning Community Right-to-Know Toxic Release Inventory (TRI) reporting. The CIS can provide information so effectively that the effort to prepare the TRI report is extensively reduced saving tens of thousands of dollars per year. Hazards assessments can also be done in a fraction of time saving resources. The Line can more effectively access their inventory and associated material safety data to minimize purchasing and waste disposal costs while reducing personnel potential exposure to hazardous chemicals. To take advantage of these opportunities addition training needs to be provided to the Line and ES\&H SMEs. Only when personnel see the tools available to them will they begin to take advantage of the innovation inherent in the new CIS. The CIS continues to be upgraded with additional features and bug fixes.

\subsection{Political/Regulatory/Legal Trends}

Prior to $9 / 11 / 2001$, chemical inventories were considered necessary for operations and regulatory reporting. However, post 9/11/2001, there has been a renewed interest in the importance of 
chemical inventories especially from the risk of chemical related terrorism. The concern of misused chemical also is focused on drug and drug precursor materials with new regulations complicating the purchasing process of some materials. The DOE is especially concerned in the area of Hazards Surveys and Hazards Assessments for Emergency Management programs and the health effects of chemical such as beryllium and NFPA Health 3 and 4 rated material. DOE at various levels from DOE HQ to DOE/NNSA/SSO have begun to raise the concern that chemical management throughout the DOE complex needs to be improved to meet operational needs and Emergency Management planning requirements. Sandia is addressing these concerns through an Issues Management Team at SNL/NM focused on chemical management. This resulted in a variety of improvements to CIS in the last several years.

Since 2008, the Alameda County Department of Environmental Health, also know as the Certified Unified Program Agency (CUPA) with jurisdiction over SNL/CA, has stepped up auditing at the site. This has resulted in a Hazards Materials Business Plan change in the form of an addition of a hazardous waste tank not previously included. It was not included previously because it was believed to only contain non-hazardous process wastewater. This change was required as part of a Notice of Violation issued in August 2010. Other CUPA driven changes have also occurred but they are out of the scope of the Chemical Management Program.

\subsection{Vulnerabilities/Failures}

The success of chemical inventory management at SNL/CA depends on hundreds of personnel performing a variety of tasks to maintain the required accuracy of the information. This is an ongoing struggle because inventory management is not the primary activity of Line personnel. Chemicals that are consumer commodities are routinely purchased from local stores and brought on-site. Since these items do not go through receiving, the Line is required to notify the CM program for barcoding service. The Line frequently fails to notify the CM program when they purchase these items, however, the containers are barcoded when they are found in the summer reconciliation. Ongoing effective training and monitoring of the data is required to maintain the desired data quality objectives of the information. A variety of improvements to CIS were implemented in the last several years addressing some of these vulnerabilities and system failures and better inventory accuracy in 2009 and 2010 suggests that these changes were effective.

\subsection{Funding Projections}

ES\&H general funding projections for FY 2012 are for no increase. As labor costs increase, a shortfall is likely. In 2011, the CM program was consolidated in the Environmental Management Department.

No significant purchases are required apart from minor desktop software upgrades for Calendar Year 2012. Travel and training costs are usually minimal at $<\$ 6,000$ per year.

The Livermore Pleasanton Fire Department CUPA, annually bills Sandia for the CUPA issued permits. This fee is based on the amount of chemical reported on the Business Plan submitted by $\mathrm{SNL} / \mathrm{CA}$ in the preceding February. The funds for this bill come from the CM budget. Due to 
the transition from our former CUPA to our present, the permit fee schedule is still being determined by the Livermore Pleasanton Fire Department.

\section{Goals and Objectives}

The CM Program is subject to internal goals and objectives established by Sandia's Integrated Mission Support Strategic Management Unit and by SNL/CA's EMS Program.

The primary goal of the CM Program is to ensure safe and effective chemical management at Sandia/CA. This is done by efficiently collecting and managing chemical information for our customers who include Line, regulators, DOE and ES\&H programs to ensure compliance with regulations and to streamline customer business processes that require chemical information. 


\subsection{SNL/CA Environmental Actions (Means) \\ FY2012 SNL/CA Environmental Actions (Means)}

Below are actions approved to achieve environmental objectives.

Objective: Demonstrate exceptional environmental performance and management.

Action 1: Maintain ISO14001 certification of SNL/CA's Environmental Management System. (Shamber)

Action 2: Support the implementation of CA elements of the SNL FY2012 Site Sustainability Plan and other environmental plans, orders, etc, as required. (Royer, Taylor, Shamber)

Action 3: Establish partnership with City of Livermore environmental and LLNL environmental elements to assure alignment of environmental program elements and share information, establish possible joint actions. (Shamber)

Action 4: Achieve SSHEAC approved reduction targets for aged chemical for each center. (FMCs)

Action 5: Achieve an overall Chemical Information System summer reconciliation of $>95 \%$. (Brynildson)

Action 6: Achieve a Chemical Information System summer reconciliation of $100 \%$ for the NFPA 704 health hazard rated 4 materials greater than $10 \%$ of laboratory scale quantities (4 lbs solid, 0.5 gal liquid, $1 \mathrm{lb}$ gas). (Brynildson)

Objective: Minimize consumption (energy, water, non-renewable resources). Action 7: Install BTU meters on chiller and boiler water systems in MANTL. (Taylor).

Action 8: Conduct energy audits of Buildings 940,941,942,916,968 and 964. (Royer)

Action 9: Deploy the web-based CA Energy Monitoring and Reporting System. (Taylor) 
Action 10: Complete the upgrade of site /building gas meters (once funding is secured). (Taylor)

Objective: Minimize the production of waste (non-hazardous, hazardous, radiological, solid, wastewater).

Action 11: Implement a plastics recycling waste stream.

Objective: Minimize air pollutant and green house gas emissions.

Action 12: Complete the installation, testing and efficient operation of all building gas boilers. (Taylor)

Action 13: Curtail fueling operations as much as possible on BAAQMD declared Spare-The-Air-Days. (Taylor)

Action 14: Take steps to curtail SF6 leakage from site electrical switchgear.

Objective: Preserve and, when possible, enhance the site's natural habitat. Action 15: Implement the most critical actions identified in the Arroyo Seco Management Plan within 10 years of receipt of the 10 year permit (Permit received Sept 25, 2008). FY12 actions include improvements \#4 and 8 for drain outlet improvements. (Royer, Taylor)

Action 16: Maintain the plantings and irrigation systems in the Arroyo Seco to support the Management Plan and permit conditions. (Taylor)

Action 17: Provide an overview briefing to the 8500 management team on the major site environmental restrictions that affect operations, site planning and execution of activities. (Shamber)

Objective: Design and manage all buildings and facilities using "green" principles.

Action 18: Initiate a landscape master plan that delineates the transition to a more environmentally friendly design including xeriscaping. (Royer) 
Objective: Maintain sewer effluent within regulatory discharge limits. Action 19: Complete the sewer sampling station modification (grinder pump mods and system failure communication to CAS). (Taylor)

Action 20: Conduct a complete pressurized sewer line cleaning annually. (next Jun 2012). (Taylor)

Action 21: Conduct CCTV inspection of all sewer lines 6 inches and greater at least every three years. (next July 2013) (Taylor)

Action 22: Conduct site sump cleaning every three years (next Jan 2014). (Taylor)

Objective: Minimize the volume and pollution of storm water runoff and other water discharges.

Action 23: Perform 100\% mechanical sweeping of streets and parting lots between Oct 1 and Nov 1 of each year. (Taylor)

Action 24: Perform 100\% cleaning of storm drain system structures (channels, catch basins, culverts) by Oct 15 of each year. (Taylor)

Objective: Procure and use environmentally friendly products and materials. No specific actions

Objective: Minimize pollutants released to the ground or ground water (spills, landscape chemicals, metals, etc..)

Action 25: Complete site deployment of covered scrap metal hoppers. (Shamber) 
Author:

Gary Shamber, Mgr. 8515

Date

Reviewed:

Craig Taylor, Mgr. 8515

Date

Howard Royer, Mgr. 8512

Date

Aden Jackson, Mgr. 8517

Date

Approved:

John Garcia, Sr. Mgr. 8510

Date 


\section{Appendix A. Personnel Assignments}

\begin{tabular}{lll}
\hline Job Assignment & Personnel & Back-Up \\
\hline Program Lead & Mark Brynildson & Robert Holland (CA)/Mary Creech (NM) \\
\hline Program Technologist & Susie Ayers & Pam Irish \\
\hline Student Intern & None assigned & None assigned \\
\hline
\end{tabular}




\section{Appendix B. Chemical Management Program Risk Assessment}

\section{Chemical Management Program Annual Risk Assessment \\ (JAN. 15, 2012)}

The risk assessment process for the Chemical Management Program follows the general steps of

1. Identify the risk

2. Identify the probability of the event occurring

3. Identify the consequence if the event occurs.

The following tables will be used to assign a numeric value to the probabilities and consequence categories.

\begin{tabular}{|c|l|}
\hline $\begin{array}{c}\text { Likelihood/Probability } \\
\text { Of Occurrence Level }\end{array}$ & Likelihood/Probability Criteria \\
\hline Very High & $\cdot$ Everything points to this occurring \\
\hline High & $\begin{array}{l}\cdot \text { High chance - Lack of relevant processes or experience contribute to a } \\
\text { high chance of occurrence }\end{array}$ \\
\hline Medium & $\cdot$ Even chance of occurrence \\
\hline Low & $\cdot$ Not much of a chance of occurrence \\
\hline Negligible & $\cdot$ Negligible chance this will occur \\
\hline
\end{tabular}

\begin{tabular}{|c|c|}
\hline $\begin{array}{l}\text { CONSEQUENCE/ } \\
\text { SEVERITY LEVEL }\end{array}$ & CONSEQUENCE/SEVERITY CRITERIA \\
\hline High & $\begin{array}{l}\text { damage (e.g., ozone depletion, rad soil contamination) } \bullet \text { Serious } \\
\text { environmental impact resulting in recovery actions lasting } 5 \text { years or } \\
\text { more (e.g., TCE in aquifer) } \bullet \text { Results in General Emergency (affects both } \\
\text { onsite and offsite) } \bullet \text { Unsatisfactory rating by external regulators or cease } \\
\text { and desist order } \bullet \text { Affects lab leadership, including prime contract } \bullet \\
\text { Actions, inactions or events that pose the most serious threats to } \\
\text { national security interests and/or critical DOE assets, create serious } \\
\text { security situations, or could result in deaths in the workforce or general } \\
\text { public (i.e., IMI-1) } 1 \cdot \text { Actions, inactions or events that pose threats to } \\
\text { national security interests and/or critical DOE assets or that potentially } \\
\text { create dangerous situations (i.e., IMI-2) }+\cdot \text { Unallowable costs or fines } \\
>\$ 1 M \text { Adverse public opinion }- \text { high interest/widespread open public } \\
\text { attention or debate (lasting weeks to months) } \bullet \text { Customer dissatisfaction } \\
\text { results in permanent loss of lab customer } \bullet \text { Catastrophic failure to meet } \\
\text { internal requirements } \bullet \text { Loss of major program within the division } \\
(>\$ 10 \mathrm{M})\end{array}$ \\
\hline
\end{tabular}




\begin{tabular}{|c|c|}
\hline Medium & 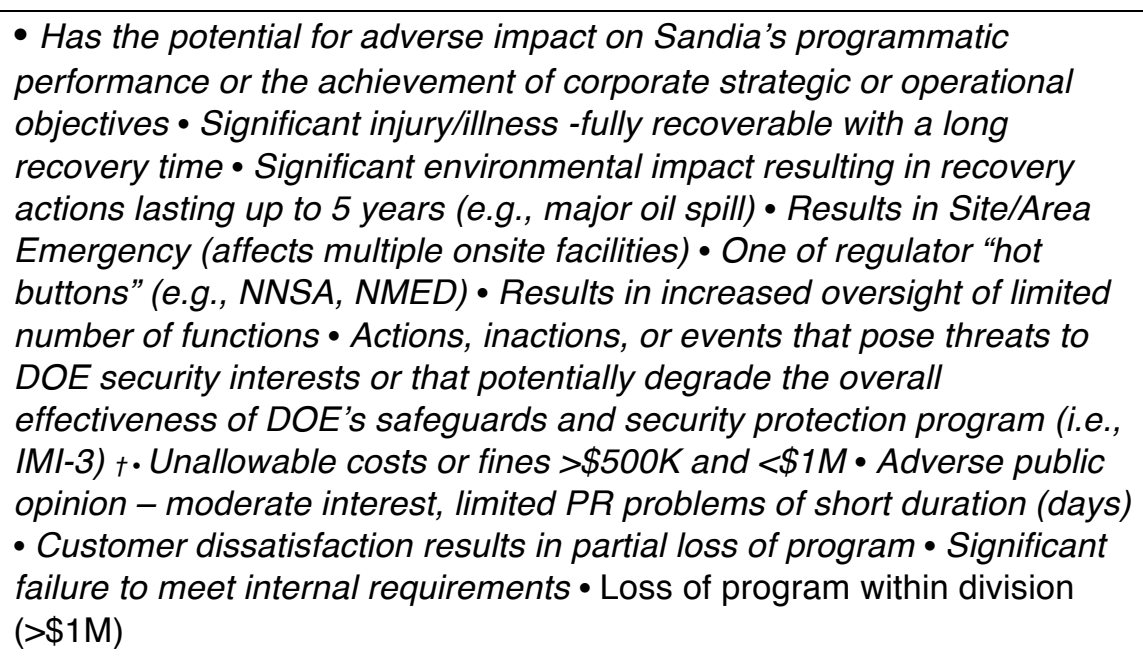 \\
\hline Low & $\begin{array}{l}\text { - Minimal injury/illness - Fully recoverable with a short recovery time } \bullet \\
\text { Minimal environmental impact that can be improved within days } \bullet \\
\text { Results in increased short-term oversight } \bullet \text { Results in an Operational } \\
\text { Emergency (affects a single onsite facility) } \bullet \text { Actions, inactions, or events } \\
\text { that could pose threats to DOE by adversely impacting the ability of } \\
\text { organizations to protect DOE safeguards and security interests (i.e., IMI- } \\
4)+\cdot \text { Unallowable costs or fines }<\$ 500 K \cdot \text { Adverse public opinion with } \\
\text { short-term local negative publicity or embarrassment }\end{array}$ \\
\hline Negligible & - Little or no attention, might be discussed as lesson learned \\
\hline
\end{tabular}

The risk level will be graded according to the following matrix.Adapted from DOE O 471.4.

\begin{tabular}{|c|c|c|c|c|c|}
\hline \multicolumn{2}{|c|}{} & \multicolumn{4}{c|}{ RISK GRADING LEVELS } \\
\cline { 2 - 6 } & Negligible & Low & Medium & High \\
\cline { 2 - 6 } & Very High & Low & Medium & High & High \\
\cline { 2 - 6 } & High & Low & Medium & High & High \\
\cline { 2 - 6 } $\begin{array}{c}\text { Likeflihood } \\
\text { Occurrence }\end{array}$ & Medium & Low & Medium & Medium & High \\
\cline { 2 - 6 } & Low & Low & Low & Low & Medium \\
\cline { 2 - 6 } & Negligible & Low & Low & Low & Low \\
\cline { 2 - 6 } & & & &
\end{tabular}




\section{Identified Risks Associated with the Chemical Management Program}

\section{Chemicals not being tracked in CIS}

2. Aging chemicals or containers

3. Chemical misidentified in CIS

4. Storage compatibility

5. Excess Inventory

6. Site-wide Earthquake Induced Spill or Accident

7. Reduction in Program Funding by $\mathbf{1 0 \%}$

\section{Regulatory Noncompliance}

\section{Chemicals not being tracked in CIS}

\section{a. Identification of Risk}

There are two methods whereby chemicals may come on-site and not be entered into the CIS database. These are 1) chemicals are purchased off-site and hand-carried onsite by the purchaser, and 2) chemicals arriving at shipping and receiving are not clearly marked as such, and are thus delivered directly to the customer's location.

\section{b. Probability of Occurrence}

The probability is low for high risk items (higher hazard), since these items can not usually be purchased at local retailers. Higher hazard items are also usually clearly identified on shipping containers. The probability for low hazard chemicals is fairly significant, since not all members of the workforce are aware of the universe of materials tracked by CIS. Therefore, the overall probability is graded as LOW.

\section{c. Consequence of Occurrence}

If chemicals are not included in CIS, it is possible that they will be stored in areas not authorized for that material. Another risk is the exceedance of the safety envelop for a specific location. This could result in a change to emergency response protocols for that facility. The consequence is graded as LOW.

\section{d. Overall Risk Category}

In accordance with the chart above, for a risk with a probability of LOW with a LOW consequence, the risk category is LOW. 


\section{Aging chemicals or containers}

\section{a. Identification of Risk}

Some chemicals become unstable with age. Examples are chemicals such as ethers that for explosive peroxides with aging.

Certain chemical containers deteriorate with age, causing a spill hazard.

\section{b. Probability of Occurrence}

The Chemical Management Program tracks the age of chemicals that form explosive compounds with age. Notices are sent to owners reminding them to remove such chemicals before they become a hazard. Approximately 20 containers per year are dealt with in this fashion.

Deteriorating containers are minimized through the efforts of the Chemical Management Program to minimize old, unused chemicals on-site.

These processes are partially manual, in that although the CIS can generate reports on age of chemicals, Chemical Management Program personnel must then manually send notices to the owners.

The probability of this risk is graded as MEDIUM.

\section{c. Consequence of Occurrence}

Aging chemicals pose a potential explosion or spill hazard. Consequences of an explosion or spill are mitigated by the fact that only small containers are typically purchased, and that they are stored in appropriate locations. The consequence is graded as LOW.

\section{d. Overall Risk Category}

In accordance with the chart above, for a risk with a probability of MEDIUM and a LOW consequence, the risk category is MEDIUM.

\section{Chemicals misidentified in CIS}

\section{a. Identification of Risk}

Chemicals are occasionally found to be misidentified in CIS. Usually the misidentification occurs when the CIS bar-code label is attached to the chemical bottle (e.g. the bar code label for a different bottle is accidentally attached). 


\section{b. Probability of Occurrence}

A few containers per year are found to be mis-identified, therefore the probability is graded as LOW.

\section{c. Consequence of Occurrence}

Misidentification in CIS does not imply that the user is not aware of the true identity of the chemical. However, the CIS database will be incorrect until the item is caught and corrected. This can lead to improper storage or the exceedance of safety envelopes, as noted above in item 1 .

The consequence of this is graded as LOW.

\section{d. Overall Risk Category}

In accordance with the chart above, for a risk with a probability of LOW and a LOW consequence, the risk category is LOW.

\section{Storage incompatibility}

\section{a. Identification of Risk}

Given the large number of chemicals on-site, there is a risk of incompatible chemicals being stored in proximity to each other.

\section{b. Probability of Occurrence}

During the reconciliation process, it has been determined that although most chemicals on-site are stored properly, a few problems can be found in most areas where large numbers of chemicals are stored. The probability is graded as MEDUIM.

\section{c. Consequence of Occurrence}

Only small quantities of the most hazardous chemicals are purchased and stored. Storage within chemical sheds, or other types of secondary containment serves to minimize the amount of incompatible materials subject to mixing. The consequence is graded as LOW.

\section{d. Overall Risk Category}

In accordance with the chart above, for a risk with a probability of MEDIUM and a LOW consequence, the risk category is MEDIUM. 


\section{Excess Inventory}

\section{a. Identification of Risk}

If the inventory of certain chemicals exceeds a regulatory threshold, SNL/CA would be required to prepare and implement an Emergency Management Program. Also, excess inventory poses an increased risk during an accidental release to personnel and the environment. Periodic surveillance of the inventory for chemical safety concerns such as explosive forming peroxidizables and autopolymerizable materials minimizes this higher risk inventory. Annual reconciliation of the inventory provides a review of the general condition of all containers and the storage conditions of these materials to minimize the risk of container failure and incompatible storage.

\section{b. Probability of Occurrence}

Given that the nature of SNL/CA's business entails the use of some extremely hazardous chemicals, and given the very low thresholds of some of these materials for requiring an Emergency Management Hazards Assessment, the probability of being required to prepare and implement an Emergency Management Hazardous Materials Program is considered to be High. Chemical safety issues relating to improper storage or the accidental release of chemicals impacting personnel and/or the environment from excess inventory is also considered to have a HIGH probability of occurrence.

\section{c. Consequence of Occurrence}

The preparation and implementation of a site-wide Emergency Management Hazardous Materials Program would very likely entail costs in the range of several hundred thousand dollars per year. These costs would be primarily borne by the Site Operations Center, since most of the activities would be carried out by the Security Operations Department and the ES\&H departments. This cost would be less than 5\% of the Site Operations budget (\$45 million in 2011), so the consequence assigned is LOW.

\section{d. Overall Risk Category}

In accordance with the chart above, for a risk with a probability of High and a Low consequence, the risk category is MEDIUM.

\section{Site-wide Earthquake Induced Spill or Accident}

\section{a. Identification of Risk}

Incidents, such as spills and fires are not unknown due to earthquakes at facilities.

\section{b. Probability of Occurrence}


Given the recent history, the probability of occurrence is considered Low that an earthquake of sizable magnitude will occur affecting SNL/CA at some time during the lifetime of the SNL/CA facility. A moderate earthquake in 1980 caused significant damage to SNL/CA include minor chemical spillage.

\section{c. Consequence of Occurrence}

SNL/CA would be responsible for the on-site clean-up and cost of waste disposal. A post cleanup inventory reconciliation would be required to verify the accuracy of the remaining inventory costing about $\$ 50 \mathrm{k}$ would be required. It is assumed that the dollar amount of the SNL/CA liability would be less than $1 \%$ of the SNL/CA annual operating budget ( $\$ 250$ million in FY 2011), therefore the consequence is Low.

\section{d. Overall Risk Category}

In accordance with the chart above, for a risk with a probability of Low, with a Medium severity, the risk category is LOW.

\section{Reduction in Program Funding by $10 \%$}

\section{a. Identification of Risk}

SNL/CA is experiencing pressure to reduce expenses for indirect-funded and directfunded organizations, including Environmental Management. Because the majority of Chemical Management Program expenditures are for labor, a 10\% reduction in funding would impact staffing. A reduction in staffing would result in a reduced level of service to line organizations.

\section{b. Probability of Occurrence}

Increasing constraints on site budgets is expected to continue for the next several years. Consequently, the probability that funding for the Chemical Management Program will decrease by 10\% from FY 2011 levels is

\section{c. Consequence of Occurrence}

A $10 \%$ reduction in program funding would result in decreased staffing, training, and purchases. Only those program activities that are required by regulation, Sandia policy, technical work documents, or DOE/NNSA would be conducted. Discretionary training and travel for program staff would be eliminated. Purchases for replacement equipment and equipment repair would be reduced. A reduction in Line training and support would occur. The suspension of the Summer Reconciliation would be likely because Summer Interns would not be hired. 
An occurrence could occur as a result Line under compliance and documentation inaccuracies. For these reasons, the consequence of a $10 \%$ reduction in program funding is identified as Medium.

\section{d. Overall Risk Category}

In accordance with the chart above, for a risk with a probability of High, with a Medium severity, the risk category is HIGH.

\section{Regulatory Noncompliance}

\section{a. Identification of Risk}

The Fire Protection Program was identified during the Fall 2008 CUPA Assessment to be under managing chemicals according to the California Fire Code (CFC) even though the CFC does not apply to federal facilities like Sandia. A similar situation exists with the International Fire Code (IFC) that is regulated by DOE. This situation has been improved by report modifications in CIS. Full IFC compliance, however, is difficult without comprehensive hazard categorization data that is not available for all the chemicals on site. This identified risk is dependent on the extent the DOE chooses to regulate the IFC at SNL/CA. All California facilities struggle with these Fire Code regulations and achieving full compliance.

\section{b. Probability of Occurrence}

The probability of an EPA, DOE, or Livermore-Pleasanton Fire Department CUPA audit resulting in a fine and/or negative publicity is Low.

\section{c. Consequence of Occurrence}

The consequence of a fine and/or negative publicity would likely be an "Unallowable cost or fine $<\$ 500 \mathrm{~K}$ " and the "adverse public opinion would be short-term local negative publicity or embarrassment". Therefore, the consequence is identified as Low.

\section{d. Overall Risk Category}

In accordance with the chart above, for a risk with a probability of Low, with a Low severity, the risk category is LOW. 


\title{
Appendix C. Chemical Management Quality Significant Purchases Determination
}

\author{
1 Sandia National Laboratories \\ Operated for the U.S. Department of \\ Energy by Sandia Corporation \\ Livermore, California 94551-0969
}

date: March 24, 2006

to: Gary Shamber, 8516

Manager, Environmental Management Department

from: Mark Brynildson, 8516

Chemical Management Program Lead

subject: Quality Significant Purchases

1.Program title. Chemical Management Program

2. Risk level of the program: The highest risk level was determined to be medium.

3. Types of material/instruments/equipment used in the program:

- PPE

- Communication devices (phones \& pagers)

- Barcodes and Barcode Scanners

- CIS database

- Desktop computers and printers

4. Criteria used to evaluate these to determine quality significance:

A potential failure of the items listed was evaluated against corporate quality-significant criteria. It was determined that such a failure:

$>$ Will not cause a significant adverse impact to program cost, schedule, or performance in the event of a failure;

$>$ Will not significantly impact the safe operation of a facility or activity;

$>$ Will not involve the use, handling, or storage of radioactive material or radiationgenerating devices, or involve exposure to ionizing radiation;

$>$ Do not relate to the design, analysis, manufacture, or assembly of hardware, equipment, and software for present or future use with radioactive material;

$>$ Will not be used in any safety-significant or safety-critical system, component, or application whose failure could adversely affect people, property, or the environment. 
5. Determination on quality significant items: The Chemical Management Program does not have any quality significant items.

6. Determination on S/CI concerns/issues: The Chemical Management Program does not have items that have the potential for suspect/counterfeit items that would be of a concern to the program. 


\title{
Appendix D. Chemical Management Program Self Assessment
}

\author{
LESA Assessment Final Report \\ Assessment ID: 13318
}

\section{Chemical Management Program Self Assessment FY12}

\section{Assessment Summary}

ID:

Title:

Description:

Purpose:

Originating

Mgt. Entity:

Assessing Org:

$\operatorname{Org}(\mathbf{s})$ Being

Assessed:

Lead Assessor:

POC Assessed:

Type:

Status:

Dates:

Result

Summary:

IA

Summary:

\section{8}

08516 Chemical Management Program Self Assessment FY12

Division 8000 Chemical Management Annual Program Assessment SNL/CA JIT Supply Chain Processes. Topics to be assessed are: Standard Program Document review: TWDs and web pages Process Level Assessment: Assessment of JIT...

\section{The Chemical Supply Chain process was significantly changed at SNL/CA with the} introduction of corporate JIT processes from SNL/NM. The gas products JIT supply chain is a mature process but the liquid and solid JIT Chem...

\section{Division » 8000 California Laboratory}

\section{Org Manager}

Division

08516 Shamber,Gary W. 08000

\section{None}

Brynildson, Mark E. (08516)

None

Line Assess the Line

Conducted

09/27/2011 - 01/31/2012

0 Significant Findings, 0 Minor Findings, 3 Observations, 0 Noteworthy Practices, 0 None (Acceptable Practices)

0 Total IAs, 0 Open IAs, 0 IAs Pending Verification, 0 Closed IAs, 0 Required IAs Missing, 0 On Track IAs, 0 Past Due IAs, 0 Causal Analyses

\section{Assessment Final Report Review}

Submitted To: Shamber,Gary W. (08516)

Submitted By: Brynildson,Mark E. (08516)

Submitted Date: 01/31/2012 


\section{Assessment Detail}

\section{Description}

Division 8000 Chemical Management Annual Program Assessment

SNL/CA JIT Supply Chain Processes.

Topics to be assessed are:

Standard Program Document review: TWDs and web pages

Process Level Assessment: Assessment of JIT Supply Chain Processes including both JIT processes, liquid \& solid chemical products - Government Scientific Sources and gas products Matheson TriGas, administrated by Org. 10248 Corporate and Strategic Purchasing. The Procurement Card Exception Process will also be assessed.

\section{Purpose}

The Chemical Supply Chain process was significantly changed at SNL/CA with the introduction of corporate JIT processes from SNL/NM. The gas products JIT supply chain is a mature process but the liquid and solid JIT Chemical Supply Chain was significantly changed at SNL/CA in 2011. Now that the process has matured to some degree it is appropriate to assess the effectiveness of the process and identify opportunities for improvement.

Analysis, Conclusions, and Additional Comments

Analysis:

Conclusions:

Additional Comments:

\section{Location(s) Assessed}

None

\section{Scope/Criteria}

- Supply Chain Management » Acquire Property, Material and Services » Other: Aquire Chemicals

\section{Checklist Used}

None

Associated Document Link(s)

None

Assessment Team Members

$\begin{array}{llll}\text { Name } & \text { Org. } & \text { Role } & \text { Additional Role Description } \\ \text { BRYNILDSON,MARK E. } & 08516 & \text { Creator } & \end{array}$

\section{Personnel Interviewed}

None

\section{Documents Reviewed}

None 


\section{Significant Findings}

This Assessment resulted in 0 Significant Finding(s).

\section{Minor Findings}

This Assessment resulted in 0 Minor Finding(s).

\section{Observations}

This Assessment resulted in 3 Observation(s).

\section{Observation No. 1}

A number of JIT Supply Chain Sandia Contracting Representative (SCR) personnel changes over the last few years at SNL/NM has led to confusion and lack of program continuity. Also, the SCR doesn't actively ensure that effective Supply Chain processes are developed, communicated to customers and assessed at SNL/CA. SNL/CA Procurement is not engaged by the SCR to provide a local Point-of-Contact or local Procurement resource.

Trending Code: Procurement

\section{Result Location(s):}

None

Result Criterion: Supply Chain Management » Acquire Property, Material and Services » Order Through Self-Service Procurement (JIT)

\section{Result Associated Document Link(s):}

None

\section{Improvement Actions(s):}

There are no Improvement Actions.

\section{Observation No. 2}

Government Scientific Sources (GSS) service charges and the ordering \& delivery delays make the Procurement Card Exception process very attractive to some SNL/CA personnel. This leads to a variety of poorly managed competing Supply Chain processes.

Trending Code: Procurement

\section{Result Location(s):}

None

Result Criterion: Supply Chain Management » Acquire Property, Material and Services » Order Through Self-Service Procurement (JIT) 


\section{Result Associated Document Link(s):}

None

\section{Improvement Actions(s):}

There are no Improvement Actions.

\section{Observation No. 3}

GSS and Matheson-TriGas delivery personnel lack clearances making deliveries and pickups inefficient in Limited Areas.

Trending Code: Procurement

\section{Result Location(s):}

None

Result Criterion: Supply Chain Management » Acquire Property, Material and Services » Other: Aquire Chemicals

\section{Result Associated Document Link(s):}

None

\section{Improvement Actions(s):}

There are no Improvement Actions.

\section{Noteworthy Practices}

This Assessment resulted in 0 Noteworthy Practice(s).

None (Acceptable Practices)

This Assessment resulted in 0 None(s) (Acceptable Practices). 


\title{
Appendix E. Chemical Management Program Self Assessment Document Checklist
}

\author{
Organization: \\ 8516 \\ Program: Chemical Management
}

\section{Date: Signature: Mark Brynildson/Susie Ayers \\ Program Lead}

\begin{tabular}{|c|c|c|c|c|}
\hline $\begin{array}{l}\text { Document } \\
\text { Type }\end{array}$ & Document Title & $\begin{array}{l}\text { Review } \\
\text { Complete } \\
\text { / Date }\end{array}$ & $\begin{array}{l}\text { Changes } \\
\text { Made }\end{array}$ & Comments \\
\hline \multirow[t]{2}{*}{$\begin{array}{l}\text { Operating } \\
\text { Procedure }\end{array}$} & AP800003 - CIS/HMMP Procedures Version D & $\bigotimes_{10 / 10 / 11}$ & $\begin{array}{l}\bigotimes \text { Yes } \\
\square \text { No }\end{array}$ & $\begin{array}{l}\text { Document needs to be } \\
\text { updated (reviewer, } \\
\text { program name) }\end{array}$ \\
\hline & $\begin{array}{l}\text { OP471758 - Semi-Annual Fire Run Card Hazardous } \\
\text { Materials Review Version F }\end{array}$ & $\begin{array}{l}\bigotimes \\
10 / 10 / 11\end{array}$ & $\begin{array}{l}\square \text { Yes } \\
\triangle \text { No }\end{array}$ & $\begin{array}{l}\text { Document needs to be } \\
\text { updated (reviewer, } \\
\text { program name) }\end{array}$ \\
\hline PHS & $\begin{array}{l}\text { Hazardous Material Management Program Operations at } \\
\text { SNL/CA (SNL0A00433-015) }\end{array}$ & \/7/11 & $\begin{array}{l}\bigotimes \text { Yes } \\
\square \text { No }\end{array}$ & \\
\hline \multirow{10}{*}{$\begin{array}{l}\text { Other } \\
\text { Program } \\
\text { Documents }\end{array}$} & $\begin{array}{l}\text { Corporate Procedure: ESH100.2.IH.20 Maintain an } \\
\text { Accurate Chemical and Biological Material Inventory }\end{array}$ & $\bigotimes_{9 / 28 / 11}$ & $\begin{array}{l}\square \text { Yes } \\
\bigotimes \text { No }\end{array}$ & $\begin{array}{l}\text { CIS Forms needs to be } \\
\text { updated }\end{array}$ \\
\hline & $\begin{array}{l}\text { CIS Program Plan (HMMP Annual Report) } \\
\text { SAND2010-1463 }\end{array}$ & $\bigotimes_{2 / 2011}$ & $\begin{array}{l}\square \text { Yes } \\
\triangle \text { No }\end{array}$ & \\
\hline & $\begin{array}{l}\text { Static Inventory Form (pdf/word) } \\
\text { http://info.sandia.gov/corpdata/corpforms/2001cif.pdf } \\
\text { http://info.sandia.gov/corpdata/corpforms/2001cif.dot }\end{array}$ & $\bigotimes_{9 / 28 / 11}$ & $\begin{array}{l}\bar{\bigotimes} \text { Yes } \\
\square \text { No }\end{array}$ & $\begin{array}{l}\text { CIS/NM mailstop needs } \\
\text { to be updated to MS } 0730\end{array}$ \\
\hline & $\begin{array}{l}\text { Gas Cylinder Form (pdf/word) } \\
\text { http://info.sandia.gov/corpdata/corpforms/2001cig.pdf } \\
\text { http://info.sandia.gov/corpdata/corpforms/2001cig.dot }\end{array}$ & $\bigotimes_{9 / 28 / 11}$ & $\begin{array}{l}\bigotimes \text { Yes } \\
\square \text { No }\end{array}$ & $\begin{array}{l}\text { CIS/NM mailstop needs } \\
\text { to be updated to MS } 0730\end{array}$ \\
\hline & $\begin{array}{l}\text { Chemical Inventory Incoming Form (pdf/word) } \\
\text { http://info.sandia.gov/corpdata/corpforms/2001cii.pdf } \\
\text { http://info.sandia.gov/corpdata/corpforms/2001cii.dot }\end{array}$ & $\bigotimes_{9 / 28 / 11}$ & $\begin{array}{l}\bigotimes \text { Yes } \\
\square \text { No }\end{array}$ & $\begin{array}{l}\text { CIS/NM mailstop needs } \\
\text { to be updated to MS } 0730\end{array}$ \\
\hline & $\begin{array}{l}\text { Biological Agent Inventory form (pdf/word) } \\
\text { http://info.sandia.gov/corpdata/corpforms/2001bai.pdf } \\
\text { http://info.sandia.gov/corpdata/corpforms/2001bai.doc }\end{array}$ & $\bigotimes_{9 / 28 / 11}$ & $\begin{array}{l}\bigotimes \text { Yes } \\
\square \text { No }\end{array}$ & $\begin{array}{l}\text { CIS/NM mailstop needs } \\
\text { to be updated to MS } 0730\end{array}$ \\
\hline & $\begin{array}{l}\text { Location Description form (pdf/word) } \\
\text { http://info.sandia.gov/corpdata/corpforms/2001cil.pdf } \\
\text { http://info.sandia.gov/corpdata/corpforms/2001cil.dot }\end{array}$ & $\bigotimes_{9 / 28 / 11}$ & $\begin{array}{l}\bigotimes \text { Yes } \\
\square \text { No }\end{array}$ & $\begin{array}{l}\text { CIS/NM mailstop needs } \\
\text { to be updated to MS } 0730\end{array}$ \\
\hline & $\begin{array}{l}\text { Chemical Transfer/Disposal form (pdf/word) } \\
\text { http://info.sandia.gov/corpdata/corpforms/2001cit.pdf } \\
\text { http://info.sandia.gov/corpdata/corpforms/2001cit.dot }\end{array}$ & $\bigotimes_{9 / 28 / 11}$ & $\begin{array}{l}\bigotimes \text { Yes } \\
\square \text { No }\end{array}$ & $\begin{array}{l}\text { CIS/NM mailstop needs } \\
\text { to be updated to MS } 0730\end{array}$ \\
\hline & $\begin{array}{l}\text { SNL Generated MSDS Request Form (pdf/word) } \\
\text { http://info.sandia.gov/corpdata/corpforms/2001msr.pdf } \\
\text { http://info.sandia.gov/corpdata/corpforms/2001msr.dot }\end{array}$ & $\bigotimes_{9 / 28 / 11}$ & $\begin{array}{l}\square \text { Yes } \\
\bigotimes \text { No }\end{array}$ & \\
\hline & $\begin{array}{l}\text { Storage Tank Registration Form (pdf/word) } \\
\text { http://info.sandia.gov/corpdata/corpforms/2001str.pdf } \\
\text { http://info.sandia.gov/corpdata/corpforms/2001str.dot }\end{array}$ & $\bigotimes_{9 / 28 / 11}$ & $\begin{array}{l}\bigotimes \text { Yes } \\
\square \text { No }\end{array}$ & $\begin{array}{l}\text { CIS/NM and CIS/CA } \\
\text { mailstops need to be } \\
\text { updated }\end{array}$ \\
\hline $\begin{array}{l}\text { Web } \\
\text { Pages }\end{array}$ & $\begin{array}{l}\text { General Web Page } \\
\text { http://info.sandia.gov/centers/8500/esh/CA- } \\
\text { EnvMgmt/programs/HM }\end{array}$ & $\bigotimes_{9 / 28 / 11}$ & $\begin{array}{l}\bigotimes \text { Yes } \\
\square \text { No }\end{array}$ & \\
\hline
\end{tabular}


Chemical Management Program Annual Report

February 2012

\begin{tabular}{|l|l|l|l|}
\hline $\begin{array}{l}\text { Program Web Pages } \\
\text { https://webprod.sandia.gov/CIS/svStartup }\end{array}$ & $\bigotimes_{9 / 28 / 11}$ & $\square$ Yes & FAQ's needs to be updated. \\
\hline
\end{tabular}

Note:

- Use this form to document review of all programmatic TWDs.

- After completion file form with your program assessment documents in the EMS adlan server.

\section{Distribution:}

MS 9956 Garcia, John., 08510

MS 9902 Shamber, Gary W., 08516

MS 0899 Technical Library, 09536 (electronic copy) 